\title{
Integration of Location-Allocation and Accessibility Models in GIS to Improve Urban Planning for Health Services in Al-Madinah Al-Munawwarah, Saudi Arabia
}

\author{
Ashraf Abdelkarim \\ Research Center, Ministry of Housing, Riyadh, KSA \\ Email: dr.ashrafgis2020@gmail.com
}

How to cite this paper: Abdelkarim, A. (2019) Integration of Location-Allocation and Accessibility Models in GIS to Improve Urban Planning for Health Services in AlMadinah Al-Munawwarah, Saudi Arabia. Journal of Geographic Information System, $11,633-662$.

https://doi.org/10.4236/jgis.2019.116039

Received: October 19, 2019

Accepted: November 10, 2019

Published: November 13, 2019

Copyright $\odot 2019$ by author(s) and Scientific Research Publishing Inc. This work is licensed under the Creative Commons Attribution International License (CC BY 4.0).

http://creativecommons.org/licenses/by/4.0/

(c) $\underset{\mathrm{EY}}{\mathrm{C}}$ Open Access

\begin{abstract}
In this study, accessibility and location-allocation models have been integrated into GIS to improve spatial planning and environmental sustainability of health services in Al-Madinah Al-Munawwarah. This integration provides a planning framework in order to check the efficiency of the spatial allocation of health services and to generate alternatives either by proposing an active service or to improve an existing one. To achieve these objectives, the accessibility to the service area was analyzed within the analysis of health services networks, which are divided into eight types: public hospitals, specialized hospitals, health units, healthcare centers, infirmaries, clinic complexes, the Red Crescent Center, and ambulance facilities, with time intervals of (5 minutes - 10 minutes - 15 minutes) to access coverage ranges, and the location-allocation model was used based on the maximum coverage model within a response time not exceeding 15 minutes, The results of the study revealed the poor distribution of health services Al-Madinah Al-Munawwarah suffers from weak accessibility to health services coverage areas and is unable to meet the needs of its population at present. The current need for health services reached twenty-four locations, including two public hospitals, three specialized hospitals, two health centers, three ambulance facilities, four infirmaries, three clinic complexes, four health units, and three Red Crescent centers.
\end{abstract}

\section{Keywords}

Urban Planning, Health Services, Accessibility, Location-Allocation Models, Geographic Information Systems, Spatial Distribution Efficiency and Equity 


\section{Introduction}

In recent years, the evaluation and planning of health services have received wide attention on the regional and urban scale because of its obvious impact on human development that requires efficient performance, which helps the city to perform its functions and activities successfully [1] [2] [3] [4]. Increasing the efficiency of health services and creating a developed residential environment has its effect on economic development. Demand for rational and accessible healthcare location planning has attracted widespread attention from researchers, planners, government agencies, especially with the global trend of massive population growth, increasing disease and environmental degradation. The problems of selecting health services locations have become increasingly noticeable in human society [5] [6], which hinder economic growth, as well as increase mortality rates in some developing cities. The treatment technology and medical equipment for most of the hospitals may not meet demand because of the underdeveloped economy [7]. Therefore, the completion of basic healthcare services should be prioritized in cities as a vital element in strategic management.

The integration of location-allocation and accessibility models provides a framework for investigating the use of health services and generating alternatives either to propose an effective service or to improve health services [8]. Accessibility to health services indicates the relative ease with which health services can be accessed from a particular location [9] [10]. Many factors may affect access to health services, such as the availability of health services in the region (supply), the size of the population in the area (demand), geographical barriers between supply and demand, and others [11].

The allocation of spatial balance of public utilities is an effective approach to maximize social welfare through rational allocation of public resources [12]. The manner of balancing equity and efficiency is an important step to achieving spatial balance in the distribution of public service resources [13]. However, in many circumstances during the city development process, the authorities concerned tended to focus more on equality or efficiency at certain stages of development, taking into account the level of social and economic development. The geographical redistribution of health services is the necessary approach to correct the misallocation of service resources. Moreover, converting public hospitals allocation from relatively sharp spatial variation to moderate equilibrium has become a major focus in some domains in recent years such as planning, management, and geography [14] [15] [16].

Many studies [17] [18] have proven the feasibility of location analysis studies in urban and regional planning services. One of the most important of these tools is quantitative modeling for accessibility analysis and location-allocation. Accessibility analysis and location-allocation modeling studies provide a spatial and quantitative comparison to assess the efficiency of previous local planning decisions and work to generate alternatives to either propose more efficient service systems or to improve existing systems where the responsible local planning 
decisions taken by governments or local leaders are often far from ideal.

It is a well-known fact that basic healthcare services cannot reach the majority of the population because of poor geographic access unless quantitative location-allocation and GIS models are used. The city's urban expansion, infrastructure development, and changes in population density affect the spatial distribution of health services, and the above challenges make the use of effective health services more difficult [19].

Researchers have many interests in studies of health services; some of them are interested in highlighting the pattern of geographical distribution of health services, and then evaluating this pattern through the study of the characteristics of beneficiaries and analysis of obstacles affecting the efficiency of these services and location selection and the impact of the location on various medical facilities [20] [21]. Bennett [22] and Phillips [23], among others, discussed location selection and the impact of the location on various medical facilities. Another trend was concerned with the spatial distribution of health services in relation to population growth rates and the evolution of the number of health service centers [24]. A third trend was concerned with using some theories to assess the distribution of health services such as the Central Place Theory and Models of Location of Facilities to improve accessibility to services and to achieve economic efficiency of distribution [25]. Others were interested in studying the regional availability model [26], nucleus density models, [27], gravity model [28], and gatherings area models [29]. Furthermore, some have turned to the use of GIS-based location-allocation models [30] [31] [32] [33] and spatial analysis and calculation [34]-[39]. Moreover, the construction or improvement of hierarchical, random, competitive multi-objective location-allocation models and other complex models have gained great interest from most planners in the last decade [31] [32] [40] [41] [42] [43].

One of the most important studies on accessibility is the study of Abdulkader [44] on the use of GIS in determining the differences in accessibility to health services in Jeddah. The study tackled the analysis of the service access area within the analysis of the road network inside GIS environment. Francisco et al. [45] study on the possibility of equitable access to health services in Extremadura (Spain), which examined network and spatial analysis to assess and guide decisions on accessibility to health services; and Peter et al. [46] study on emergency services planning using Geographic Information Systems based on geographic accessibility analysis. The study examined the methodology of analyzing the service access area within the analysis of the road network within the GIS environment.

The study of Rudzi and Fini [47] on the development of accessibility models to maximize the overall service area by application to fire stations in Jakarta, Indonesia, where the study dealt with a methodology that develops the analysis of the service access area within the analysis of road networks within the GIS environment to maximize the service area as well as the Honadi study [48] on mea- 
suring access to primary health care centers in Johannesburg, where the study examined access to primary health care centers in an urban area, using the methodology to analyze the service access area in the analysis of road networks within the GIS environment.

As for studies on location-allocation, there is a study by Rahman and Smith [8] on the use of location-allocation models in health service development planning in developing countries. This study tackled the suitability of the location-allocation models to design health care systems and its importance in relevance to the problems of overall development in those countries, and the Gustavo study [49] on location-allocation models applied to urban public services. The spatial analysis of primary health care centers in Logan, Argentina, where the study examined the spatial analysis of health care centers using allocation models in the GIS software and the identification of suitable locations for the establishment of new health centers for equitable spatial distribution, and the Gina et al. study [50] on the location-allocation and accessibility models to improve spatial planning for public health services. The study examined the integration of accessibility and location-allocation models in GIS as a proposed strategy for improving spatial planning for public health services.

Tom and Edward's study [51] on a GIS-based location-allocation model for improving access to health care facilities in Mount Elgon sub-district, the study examined the use of the GIS-based allocation model to improve geographical accessibility to health care services in the Elgon sub-district, and the Irene et al. study [52] on the improvement of the problem of location-allocation for pharmaceutical warehouses: a case study in Gaziantep, where the study dealt with the improvement of the problem of allocating the locations of pharmaceutical warehouses by applying to a city (Gaziantep) using the mathematical models P-center and P-median.

Beheshtivar et al. [53] introduced a multi-goal location-allocation model that takes into account four objectives: reducing overall travel cost, unequal access to the clinic, incompatibility of land use in the study area, land acquisition costs and establishment of a facility in optimal locations for new clinics. Weidner and Horner [54] presented a model for the average hierarchy model based on GIS and strategies for spatial improvement to identify relief distribution points, the model aims to reduce travel costs for the different demand levels associated with the appropriate facility providing different relief services.

Through the presentation of previous studies, it has been found that there is no study in the field of the subject of the current research, which is the integration of accessibility models and the allocation of location in GIS in order to improve the spatial planning of health services conducted in Al-Medina, and therefore this study is unique as one of the first Studies in the Arab Library that apply this approach to Al-Medina, it is also noticeable that there is a section of these studies listed in the context of previous studies consistent with the previous study in improving the spatial planning of health services by applying ac- 
cessibility models and customizing the site in systems Geographical information.

The current study to improve the spatial planning of health services in AlMadinah Al-Munawwarah emphasizes the hypothesis that neglecting the assessment and planning of health services and its integration with accessibility models and location-allocation leads to the shrinking of an essential part of the land use in Al-Madinah Al-Munawwarah and prejudices the requirements of its success. This leads to the lack of a suitable environment to meet the health needs of the population.

This study seeks to determine the efficiency of the spatial distribution of health services and its compatibility with the distribution of residential districts in Al-Madinah Al-Munawwarah, and to verify the functional appropriateness required and propose new locations according to a new and unique approach combines accessibility to assess the efficiency of the spatial distribution of health services and to determine the current and future needs of different health services in Al-Madinah Al-Munawwarah according to the application of location-allocation models.

\section{Study Area}

Al-Madinah Al-Munawwarah is located northwest of Saudi Arabia at the confluence of longitude $39^{\circ} 36^{\prime} \mathrm{E}$ with latitude $24^{\circ} 28^{\prime} \mathrm{N}$ and its area is $590 \mathrm{~km}^{2}$. The built area covers about half this area and the city is about $150 \mathrm{~km}$ away from the city of Yanbu' on the Red Sea coast to the west, the latter is the sea gate for the visitors of the city. Al-Madinah Al-Munawwarah is $400 \mathrm{~km}$ away from Jeddah, the main port, and it is $980 \mathrm{~km}$ away from Riyadh, the capital of the Kingdom (Figure 1, Figure 2).

Al-Madinah Al-Munawwarah is considered the second most important Islamic cities after Holy Mecca. Its importance is derived from the presence of the Prophet's Mosque; Al-Madinah is also one of the holy cities that non-Muslims are not allowed to visit. Al-Madinah occupies a natural hillside basin more than 600 meters above sea level. The city is surrounded by a group of volcanic mountains, with the exception of its northern sides.

The population of Al-Madinah Al-Munawwarah doubled during the period 1974-2019 nearly 7.5 times from 198,055 people in 1974 to $1,487,478$ people in 2019 as a result of the natural increase on the one hand and the increase in the population of arrivals. The increase during this period was about $1,289,423$ people, and the increase was spread over 45 years, with a growth rate of $4.58 \%$ and an average annual increase of 28,654 people during that period. The period 1974-1992 is the highest rate of population growth in the history of Al-Madinah Al-Munawwarah as the annual growth rate has reached $6.44 \%$, while the period 2013-2016 reached the highest average annual increase by 37,224 people.

\section{Study Methodology and Data Processing}

This study combines performing accessibility analysis based on service area 
analysis to assess the current situation of health services in Al-Madinah Al-Munawwarah and determine the coverage area according to the established time intervals and analysis of the location-allocation to plan for the future of health services in Al-Madinah Al-Munawwarah, identify the deficit, and suggest new suitable locations for them if necessary. Network analysis within the GIS environment is one of the most important tools used for this purpose for its close connection with the road network, which is the main means of transport. Also, some methods of spatial and statistical analysis were used in GIS when evaluating the type of spatial distribution of health services. The methodology of assessing and planning health services in Al-Madinah passed through five main stages through a software Arc GIS as shown in Figure 3.

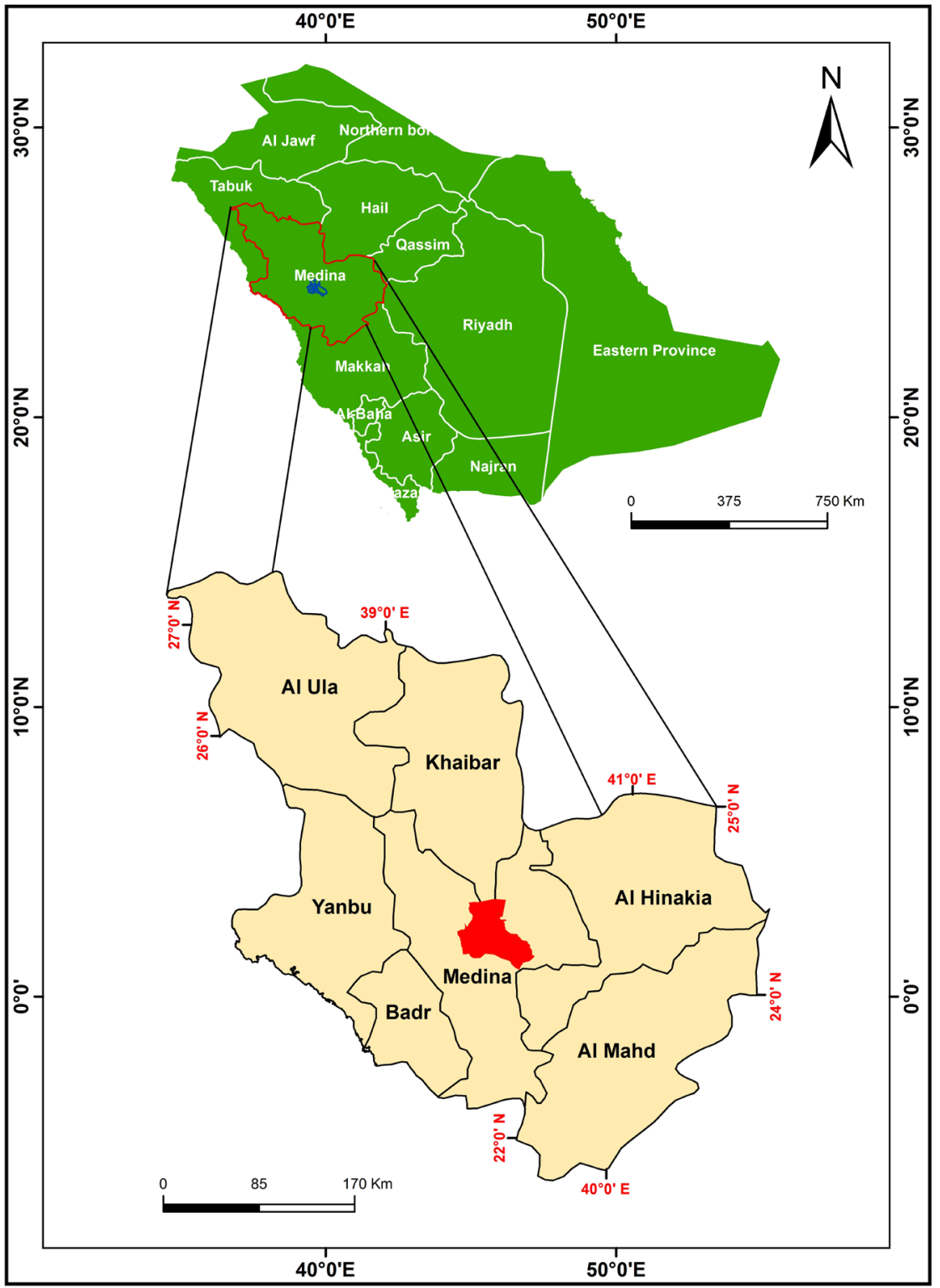

Figure 1. The location of AL-Madinah Al-Munawwarah in the Kingdom of Saudi Arabia in 2019 . 


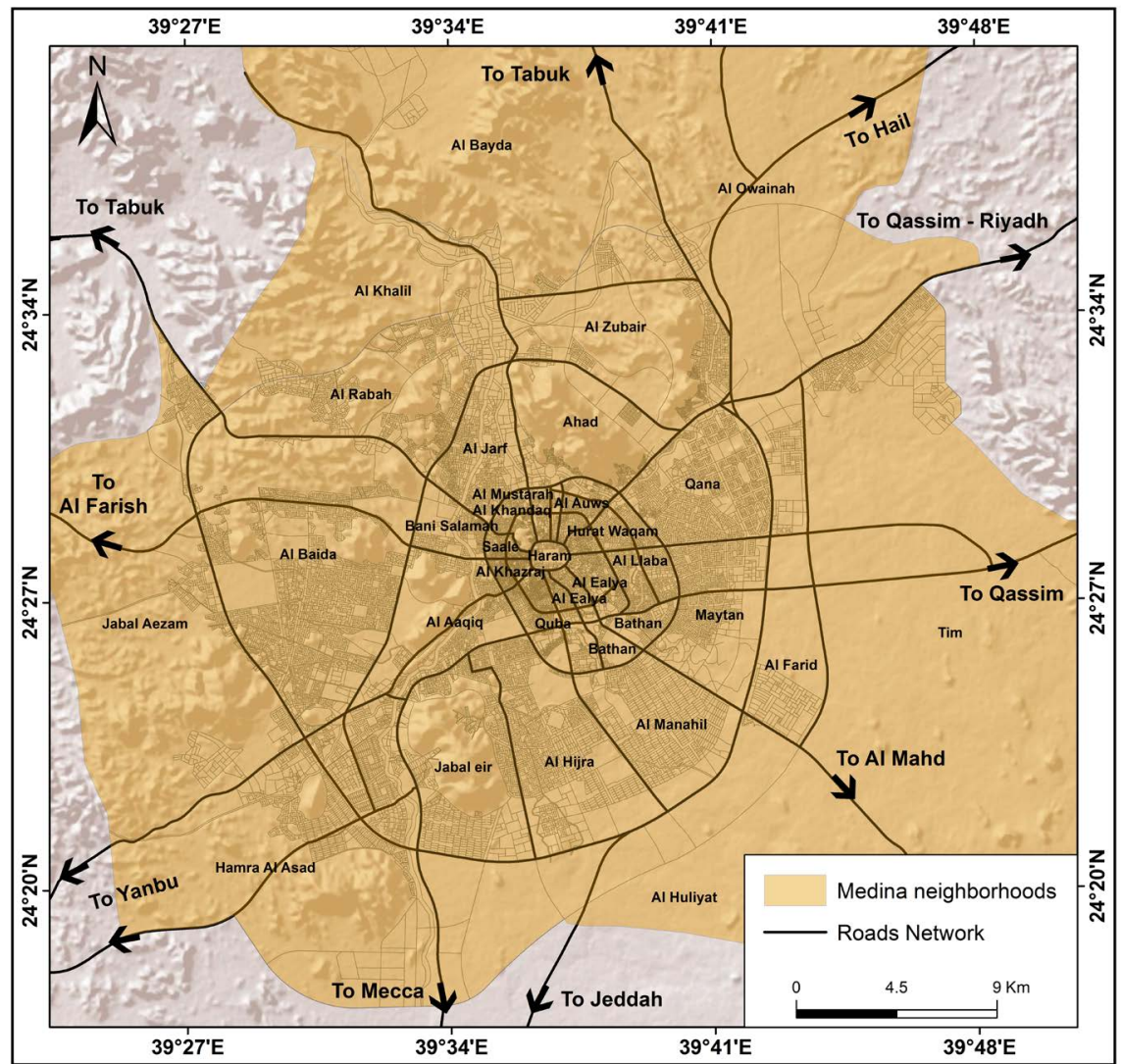

Figure 2. The districts of Al-Madinah in 2019.

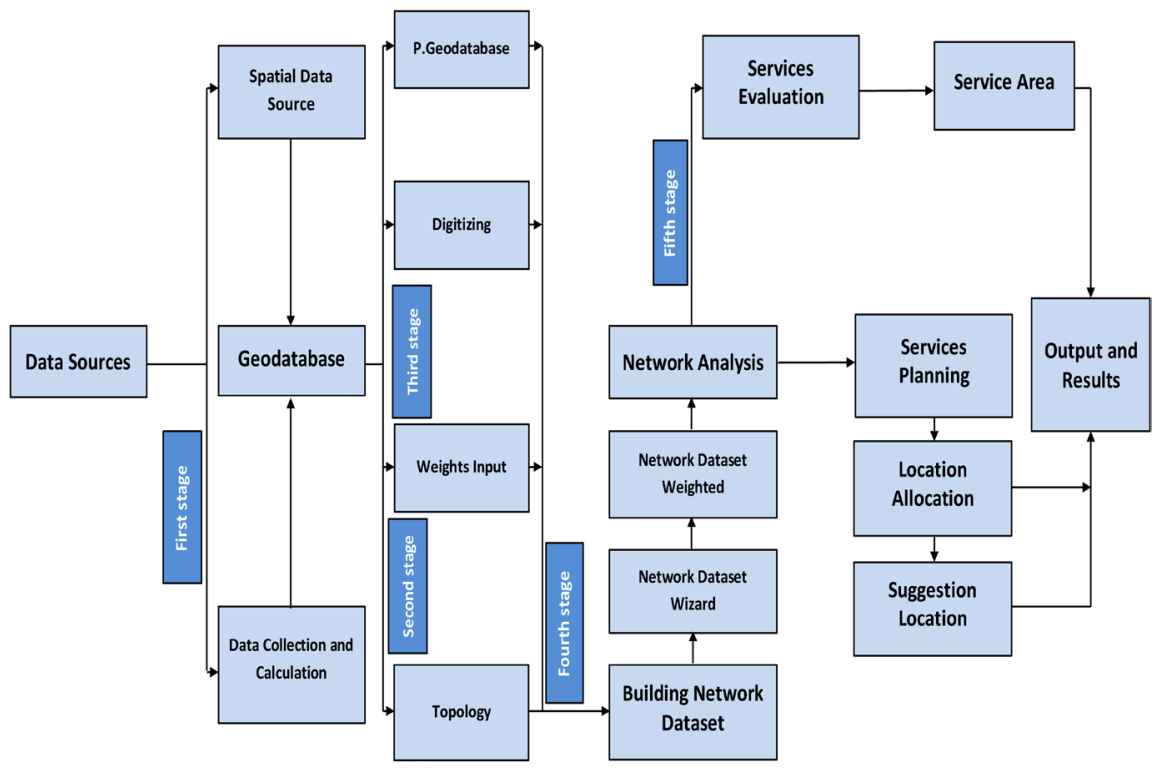

Figure 3. Stages and methodology of work followed in the study.

The first stage was the collection of data needed to analyze surface networks such as road and service location layers, and descriptive information such as road link information (distance, time spent, waiting, speed, and directions), and all spatial data were then incorporated into a unified projection system to conso- 
lidate outcomes and outputs.

The second stage was the implementation of topological construction on the roads layer in order to look for problems and spatial faults in them and treat them according to spatial controls of the surface network analysis. The third stage dealt with recording the metadata of the road links to the attribute table to function as weights for comparison when analyzing surface networks.

The fourth stage dealt with the construction of the road-network Network Dataset on the road layer after processing and recording weights within the GIS environment. The fifth stage is conducting accessibility analysis based on Service Area analysis to assess the current situation of the health services in Al-Madinah and determine the area of coverage according to time intervals (5 minutes - 10 minutes - 15 minutes). The implementation of analysis comes after the construction of the road network, where the analysis layer is added from the surface network analysis toolbar Network Analysis After activation, the properties of the analysis layer are then defined such as: Impedance Weight (distance or time) and its value, and configuration of outputs on the boundaries of the road network Trim Polygon, and merging the resulting domains (Merge by Default Break), after configuring the analysis layer properties.

The spatial location layer for services Facilities has been added inside theNetwork Analysis Window, And network solution Solve to obtain the results, the results were divided on the administrative boundaries of the study area to determine the percentage of service coverage from each administrative department and to determine the degree of coverage. Figure 4 shows the constructional model for analyzing the accessibility to health services in Al-Madinah Al-Munawwarah.

Stage five also included a location-allocation analysis Location-Allocation To plan the future of health services in Al-Madinah, identify the deficit, and suggest new suitable locations for them, if necessary, and the implementation of this analysis comes after the construction of the road network, where the analysis layer is added from the surface network analysis toolbar Network Analysis after it is activated, the properties of the analysis layer (such as the standard of analysis Impedance Weight (Distance or time), its value, and the number of allocation services Facilities to Choose, and allocation duration Impedance Cutoff, type of allocation model Location Problem Type. Figure 5 shows the structural model for the analysis of the allocation of the location to health services in Al-Madinah.

The analysis of location-allocation includes seven models [55] [56], and the maximum coverage model [8] has been used, whose formula states:

$$
\operatorname{Maximize}\left\{F=\sum_{i \in I} a_{i} x_{i}\right\}
$$

where: I: Set of demand points, a_i: Distance between request coverage limits, viewpoints, time duration, or population as weight, $x_{-}$i: Site allocation coefficient with only two values $(0,1)$.

After configuring the analysis layer properties and choosing the type of allocation, the spatial locations of the services were added facilities and the demand 
pointsDemand Pointwere added, which are the administrative sections of the study area after they have been converted to a bitmap layer within a window Network Analysis Window, and network solution Solve For the results, additional sites were proposed for the services to be allocated to all administrative departments of the study area.

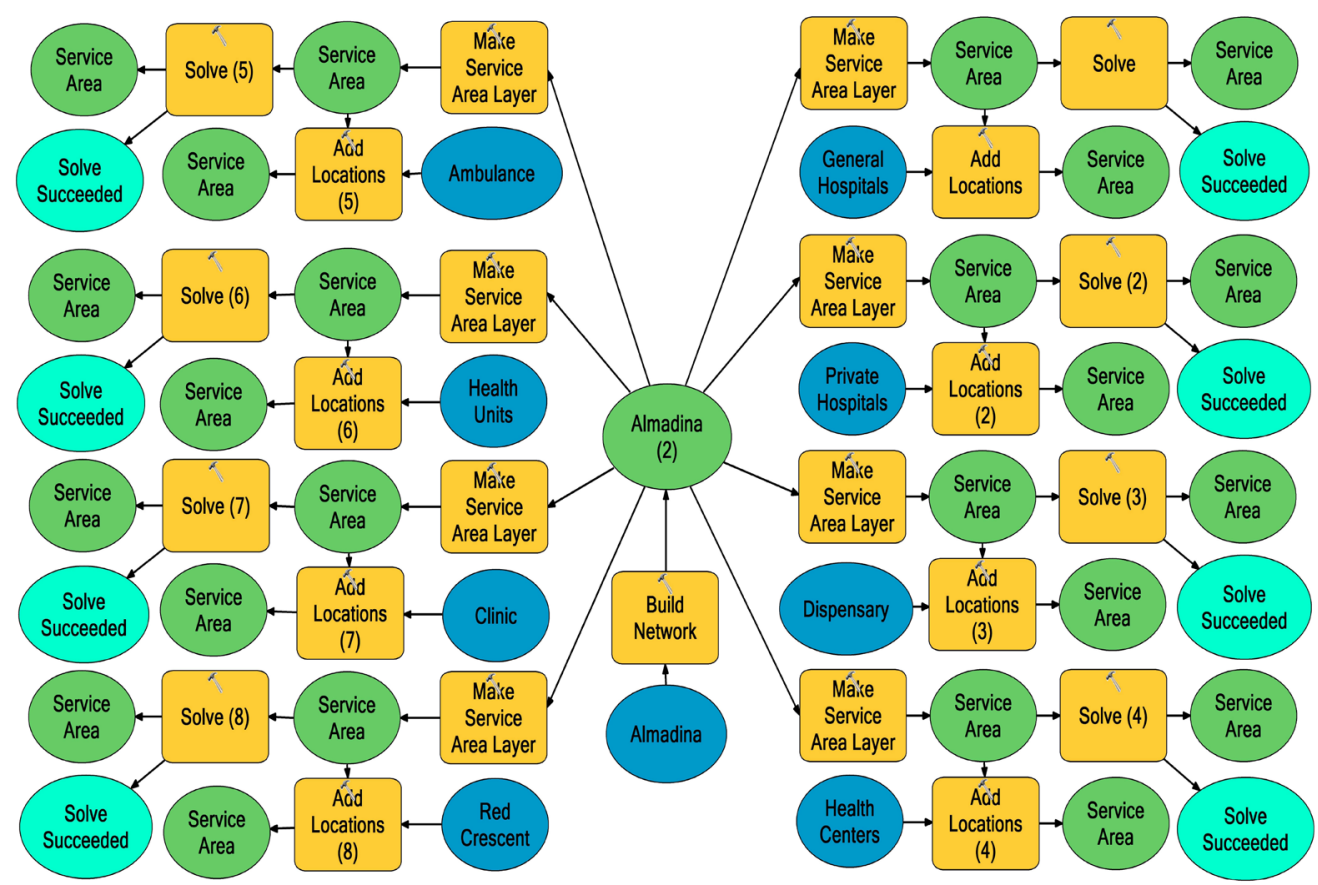

Figure 4. Structural model for accessibility analysis of health services in Al-Madinah.

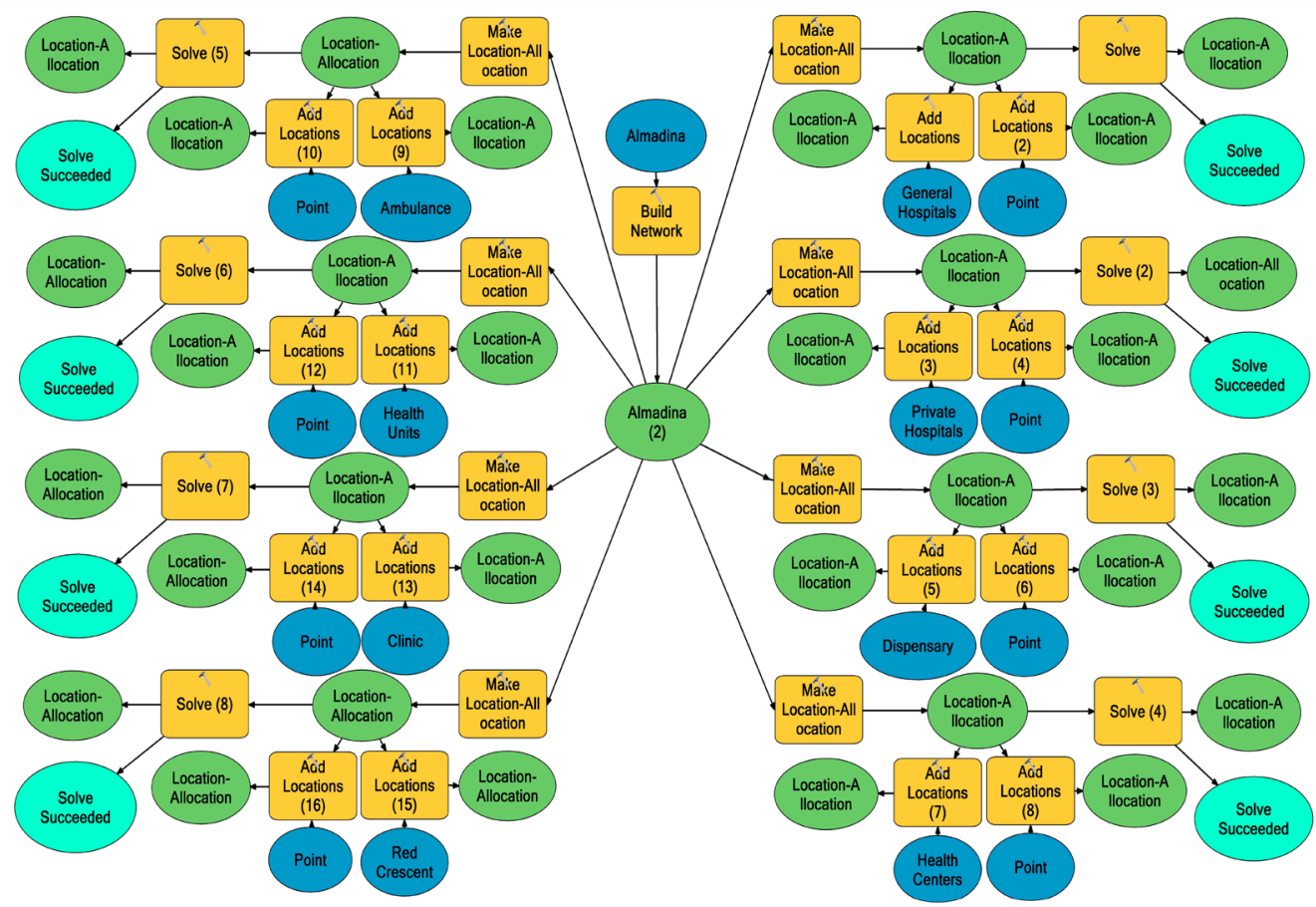

Figure 5. Structural model of location-allocation analysis for health services in Al-Madinah. 
The study was based on the official government digital sources provided by the Secretariat of Al-Madinah. Almost eleven digital layers were obtained, and they are represented in the layers: the administrative boundaries of Al-Madinah, the administrative division of Al-Madinah, and the boundaries of districts of $\mathrm{Al}$ Madinah, and the provision of about eight different layers of health services including hospitals, public hospitals, specialized hospitals, health units, infirmaries, clinic complexes, health centers, Red Crescent centers and ambulance facilities.

\section{Results and Discussion}

\subsection{Accessibility Analysis for Health Services in Al-Madinah}

\subsubsection{Public Hospitals}

The results of the accessibility to public hospitals service during the five, ten and fifteen minute intervals, (Figure 6), revealed that the districts that can access the public hospitals service within five minutes via the road network and according to the speed limit are 88 districts out of the 107 districts in Al-Madinah with a percentage of $82.2 \%$ of the total number of Al-Madinah districts. The number of districts that cannot access public hospitals within five minutes are 19 districts which make up $17.8 \%$ of the total districts of Al-Madinah and these districts are: Nubala'a, Rahat, Al-Jissah, Bani Bayada, Al-Sharae', Umm As-Suyouf, Khakh, Al-Muzayin, Al-Naqmi, Al-Sahwa, Al-Sadd Al-Ghaba, Al-Ghaba, Al-Sadeqiya, Al-Mufrahat, the Industrial City, Al-Sahlouj, Al-Balqa'a, Kittaneh and Wadi Al-Hamd, while all districts of Al-Madinah Al-Munawwarah can reach public hospitals in ten minutes, fifteen minutes via the road network according to the speed limit.

\subsubsection{Specialized Hospitals}

The results of the accessibility to the specialized hospitals service during the intervals of five, ten and fifteen minutes, (Figure 7), revealed that the districts that can access the service of specialized hospitals within five minutes through the road network and according to the speed limit are 79 districts out of the total number of the 107 districts in Al-Madinah with a percentage of $73.8 \%$. The number of districts that cannot access the service of specialized hospitals within five minutes is 28 districts which constitute $26.7 \%$ of the total districts in Al-Madinah and these districts are: Rahat, Al-Jissah, Sharae', Umm As-Suyouf, Khakh, Al-Muzayin, Al-Naqami, Al-Matar, Al-Khadra', Abu Sidr, Sahwa, Sadd Al-Ghaba, Al-Ghaba, Al-Aqoul, Al-Anahi, An-Nakhil, As-Sadeqiya, Al-Mafrahat, The Industrial City, Wadi Al-Battan, Hududa', Tayba, Sahlouj, Balqa', Az-Zahra, Kittaneh, Al-Hafia, and Wadi Al-Hamed, and the number of districts that can reach specialized hospitals services during ten minutes through the road network according to the speed limit are 106 districts of the 107 districts of Al-Madinah which constitute $99.1 \%$ of the total districts of Al-Madinah.

The number of districts that cannot access the specialized hospitals service within ten minutes is one district which constitutes $0.9 \%$ of the total districts of Al-Madinah, the district of As-Sahwa, while all districts of Al-Madinah can 
reach the service of specialized hospitals within fifteen minutes via the road network and according to the speed limit.

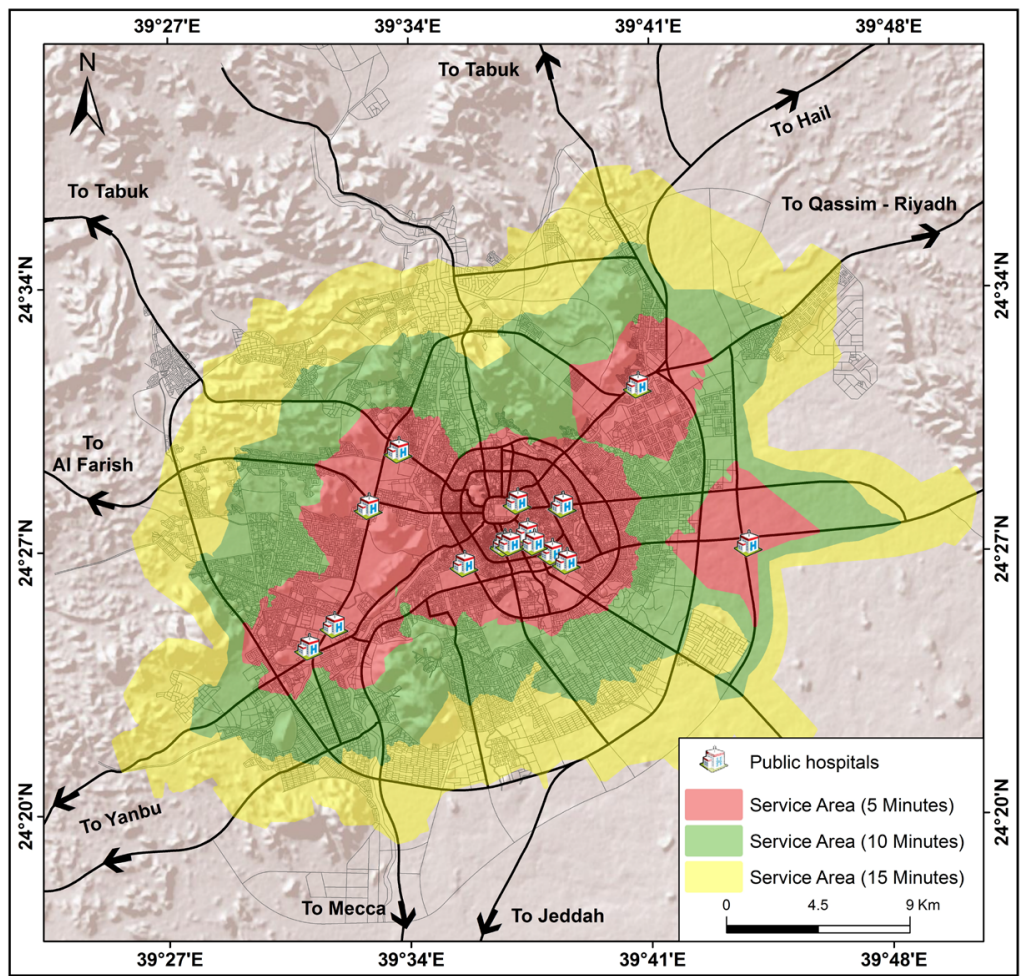

Figure 6. Accessibility to public hospitals based on service area analysis.

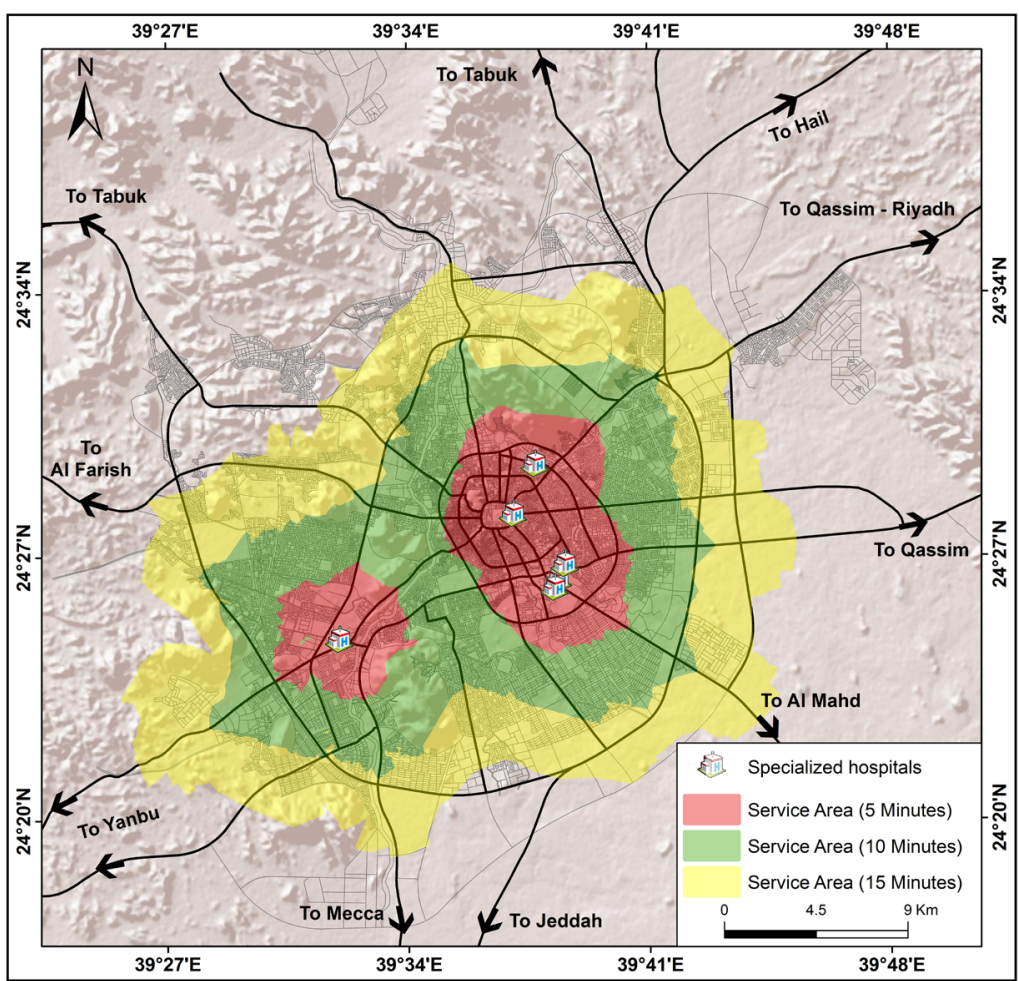

Figure 7. Accessibility to Specialized hospitals based on service area analysis. 


\subsubsection{Primary Health Centers}

The results of the accessibility of the PHC service during the five, ten and fifteen minute intervals, (Figure 8), revealed that the districts that can access the PHC service within five minutes via the road network according to the speed limit are 90 out of the 107 districts in Al-Madinah which constitutes $84.1 \%$ of the total number of districts in Al-Madinah. The number of districts that cannot access the primary health centers within five minutes 17 districts which constitutes $15.9 \%$ of the total districts of Al-Madinah which are Al-Jissah, Sharae', Umm As-Suyouf, Khakh, Al-Muzayin, Al-Naqami, As-Sahwa, Sadd Al-Ghaba, Al-Mafarahat, The Industrial City, As-Sahlouj, Al-Balqa', Al-Anahi, Ar-Rummanah, Wadi Al-Battan, Hududa', and Wadi Al-Hamed while all Al-Madinah districts can access PHC service within time intervals of ten and fifteen minutes through the road network according to the speed limit.

\subsubsection{Infirmaries}

The results of the accessibility to the infirmaries service within the five, ten and fifteen minute intervals, (Figure 9), the number of districts that can access the infirmaries service within five minutes through the road network according to the speed limit is 81 out of the 107 districts in Al-Madinah which constitutes $75.7 \%$ of the total number of districts in Al-Madinah. The number of districts that cannot access the infirmaries within five minutes are 26 districts which constitutes $24.3 \%$ of the total districts in Al-Madinah and these districts are: Rahat,

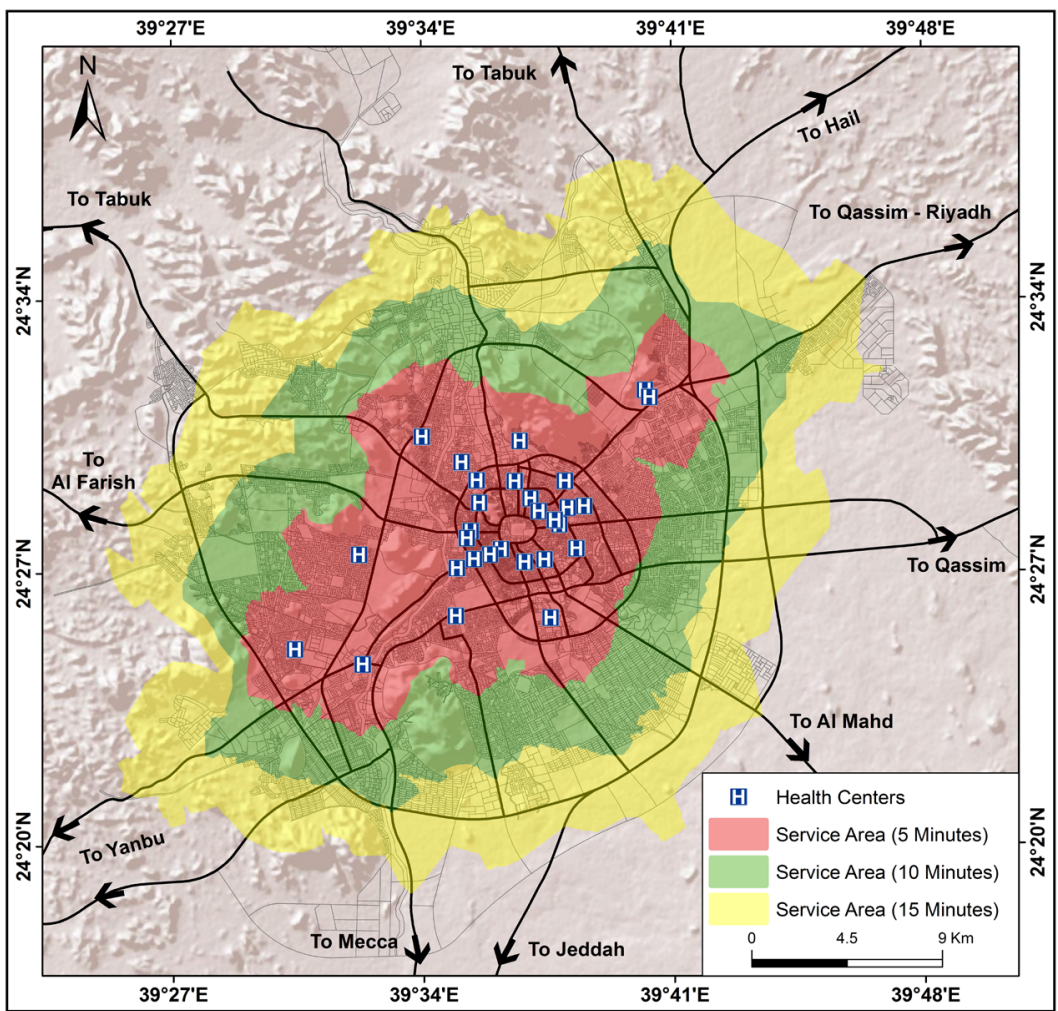

Figure 8. Accessibility to health centers based on service area analysis. 


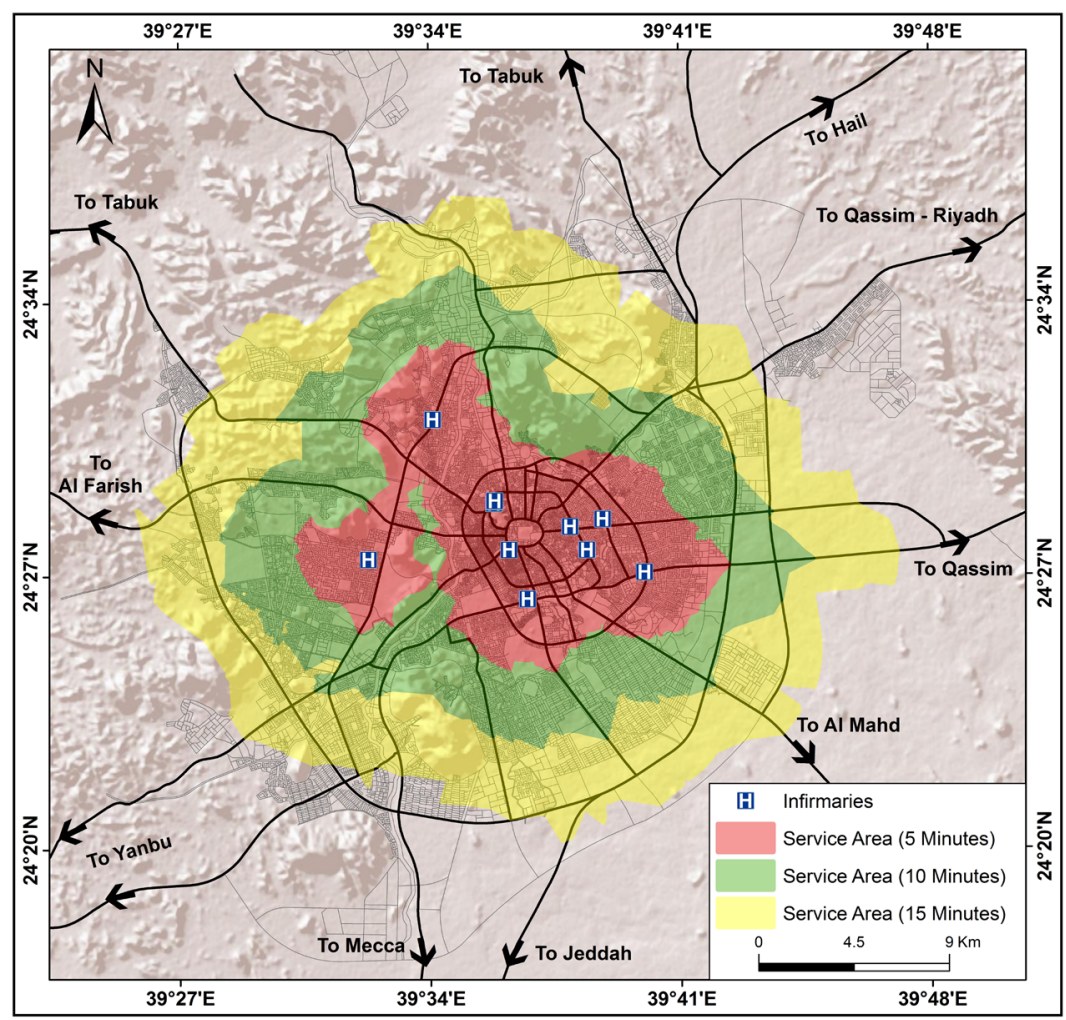

Figure 9. Accessibility to infirmaries based on service area analysis.

Al-Jissah, Sharae', Umm As-Suyouf, Khakh, Al-Muzayin, An-Naqami, Al-Matar, Al-Khadra', Abu Sidr, As-Sahwa, Sadd Al-Ghaba, Al-Mufrahat, the industrial city, As-Sahlouj, Al-Balqa, Bani Bayada, Nubala', As-Sakb, Ash-Shahba'a, AshShafiyah, "Ayra, Al-Sina'ah, Al-Hasa”, Warkan, and Abu Markhah. The number of districts that can access the infirmaries service within ten minutes via the road network and according to the speed limit are 106 districts out of 107 districts in Al-Madinah which constitutes $99.1 \%$ of the total districts in Al-Madinah. The number of districts that cannot access the infirmaries services within 10 minutes is one district which is $0.9 \%$ of the total districts in Al-Madinah, which is As-Sahwa district. All of the districts in Al-Madinah can access the infirmaries service within fifteen minutes through the road network according to the speed limit.

\subsubsection{Ambulance Facilities}

The results of the accessibility to the ambulance service during the five, ten and fifteen minute intervals, (Figure 10), the number of districts that can access the ambulance service within five minutes is 72 districts of the 107 districts in Al-Madinah which constitutes $67.3 \%$ of the total number of districts in Al-Madina, and the number of districts that cannot access the ambulance 35 districts which constitutes $32.7 \%$ of the 107 districts in Al-Madinah which are Rahat, Al-Jissa, Al-Sharae', Umm As-Suyouf, Khakh, Al-Muzayin, An-Naqmi, AlMattar, Al-Khadra', Abu Sidr, As-Sahwa, Sadd Al-Ghaba, Al-Ghaba, Al-Aqoul, 
Al-Anahi, As-Saiqiyah, Al_mifrhat, the industrial city, Wadi Al-Battan, Hadouda', AS-Sahlouj, Wadi Al-Hamed, Al-Ghara', Ar-Roumanah, Nubala', As-Sakb, Eira, Ash-Shafiyah, Al-Hisa', Warkan, Ein Al-Kheif, As-Sina'eiah, As-Sikka, Abu Markha, and Katana. The number of districts that can access the ambulance service within ten minutes via the road network and according to the speed limit is 103 of the 107 districts in Al-Madinah which is $96.3 \%$ of the total districts in Al-Madinah, the number of districts that cannot access the ambulance facilities service within ten minutes are four districts which make $3.7 \%$ of the total districts in Al-Madinah and these districts are: Abu Sidr, As-Sahwa, As-Sahlouj, and Al-Balqa', while all districts in Al-Madinah can access the ambulance facilities service within fifteen minutes via the road network according to the speed limit.

\subsubsection{Clinics Complex}

The results of the accessibility to the clinics complexes service within five, ten and fifteen minute intervals, (Figure 11), revealed that the districts that can access the clinics complexes service within five minutes via the road network and according to the speed limit are 72 districts of the 107 districts in AL-Madinah which constitutes $67.3 \%$ of the total number of districts in Al-Madinah. The number of districts that cannot access the clinics complexes service within five minutes are 35 districts constituting $32.7 \%$ of the total districts in Al-Madinah and these districts are: Warhat, Al-Jissah, Ash-Sharae',

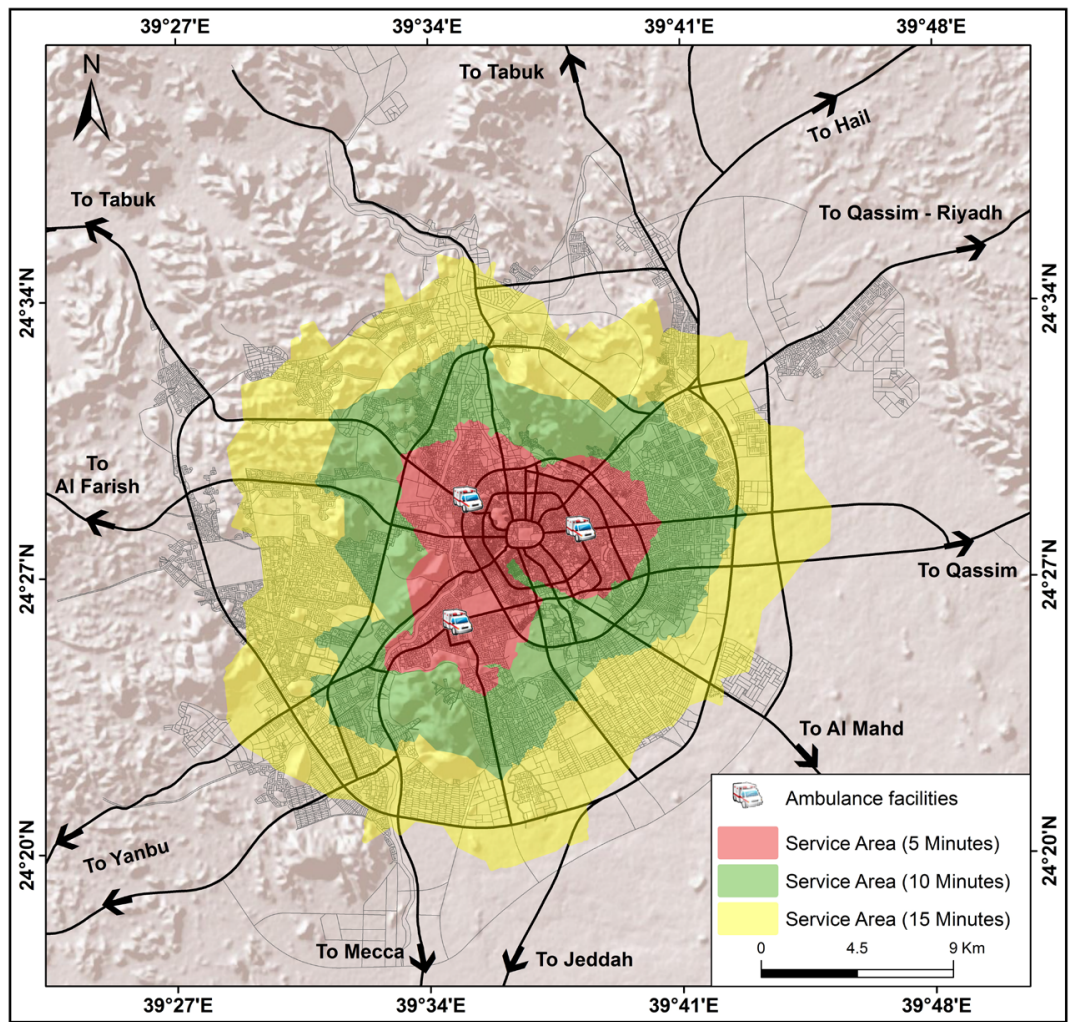

Figure 10. Accessibility to ambulance facilities based on service area analysis. 


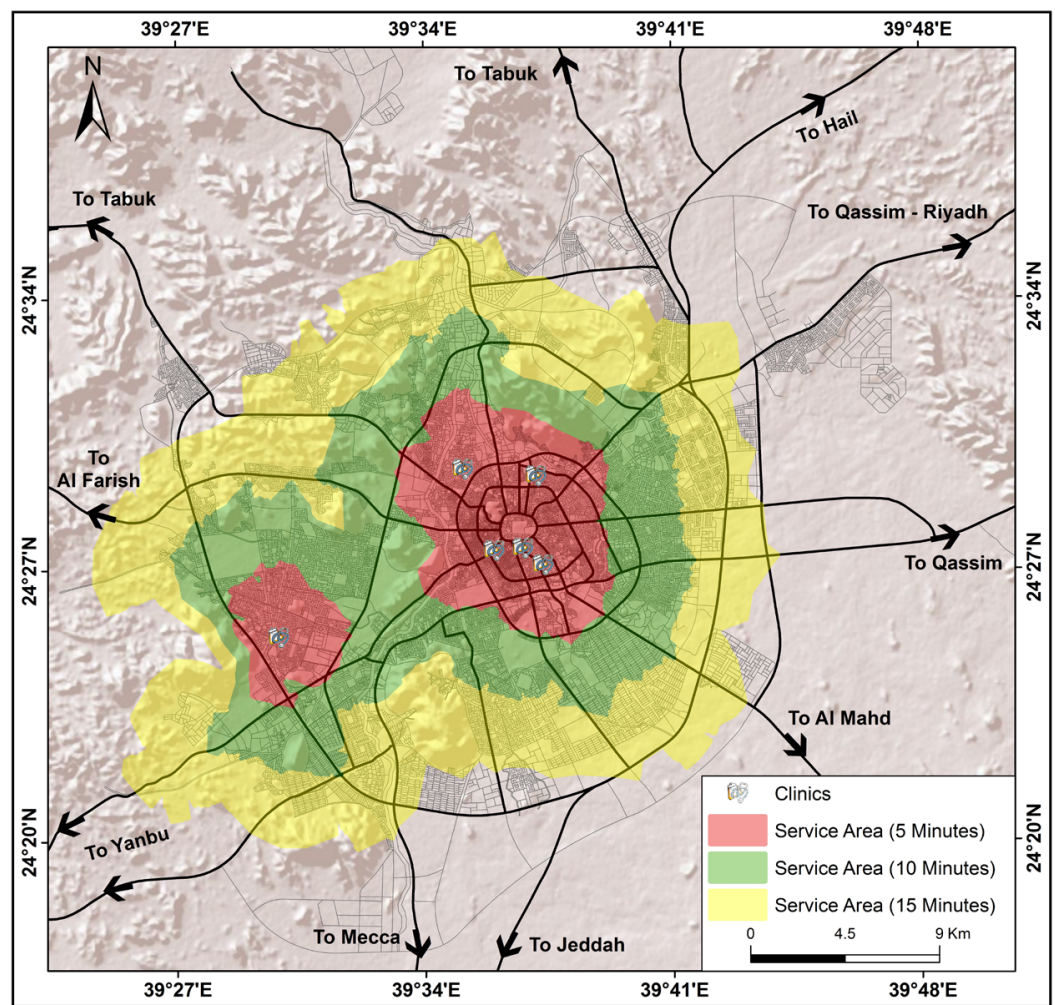

Figure 11. Accessibility to clinic complexes based on service area analysis.

Umm Al-Suyouf, Khakh, Al-Muzayin, An-Naqmi, Al-Matar, Al-Khadra', Abu Sidr, As-Sahwa, Sadd Al-Ghaba, Al-Mufrahat, the Industrial City, As-Sahlouj, Al-Balqa', Nubala', As-Sakb, Al-Shafia, Aira, Al-Hassa', Bani Bayada, Ar-Rummanah, Jabal Ir, Al-Ghaba, Al-Aqol, Al-Anahi, King Fahd, Ain Al-Khaif, AlHadraa, Hadawda', Kattanah, Al-Hafia, Wadi Al-Hamed, and Wadi Al-Battan. The number of districts that can access the service of clinics complexes within ten minutes via the road network according to the speed limit is 105 districts out of the 107 districts in Al-Madinah which constitutes $98.1 \%$ of the total number of districts in Al-Madinah,

The number of districts that cannot access the clinics complexes service within ten minutes is two of the districts constituting $1.9 \%$ of the total number of districts in Al-Madinah and these districts are: As-Sahwa and Abu Sidr, while all districts in Al-Madinah can access the clinics complexes service within fifteen minutes via the road network according to the speed limit.

\subsubsection{Health Units}

The results of the accessibility to the health units service within five, ten and fifteen minutes time interval, (Figure 12), revealed that the districts that can access the health units service within five minutes via the road network and according to the speed limit are 68 districts of the 107 districts in Al-Madina constituting $63.6 \%$ of the total number of districts in Al-Madinah. The number of districts that cannot access the health units service within five minutes are 39 districts 
constituting $36.4 \%$ of the total number of districts in Al-Madinah. These districts are: Ash-Sharae', Umm As-Suyouf, Khakh, Al-Muzayin, An-Naqmi, AlMatar, Al-Khadra', Abu Sidr, As-Sahwa, Sad Al-Ghaba, the industrial city, As-Sahlouj, Al-Balqa', As-Sakb, Al-Hasa', Ar-Rummanah, Al-Ghaba, Al-Aqol, Al-Anahi, Ein Al Kheif, Al-Hadra', Hadouda', Kattanah, Al-Hafia, Wadi AlHamed, Wadi Al-Battan, Ash-Shafiyah, Ash-Shahba', As-Sina'ya, Abu Kabir, Warkan, As-Saiqiyah, As-Salam, Al-Mifrhat, As-Sikka, Abu Markha, Az-Zuhra, Ad-Difa', and Al-Aziziah. The number of districts that can access the health units service within ten minutes via the road network according to the speed limit is 102 districts out of the 107 districts in Al-Madinah which constitutes 95.3\% of the total number of districts in Al-Madinah. The number of districts that cannot access the health units service within ten minutes is five districts constituting $4.7 \%$ of the total number of districts in Al-Madinah and these districts are: As-Sahwa, Al-Mifrhat, the industrial city, As-Sahlouj, and Al-Balqa'. All districts in Al-Madinah can access the health units service within fifteen minutes via the road network according to the speed limit.

\subsubsection{Red Crescent}

The results of accessibility of the Red Crescent service within five, ten and fifteen minutes intervals, revealed that the districts that can access the Red Crescent service within five minutes via the road network and according to the speed limit 76 districts of the 107 districts in Al-Madinah constituting 71\% of the total number of districts in Al-Madinah.

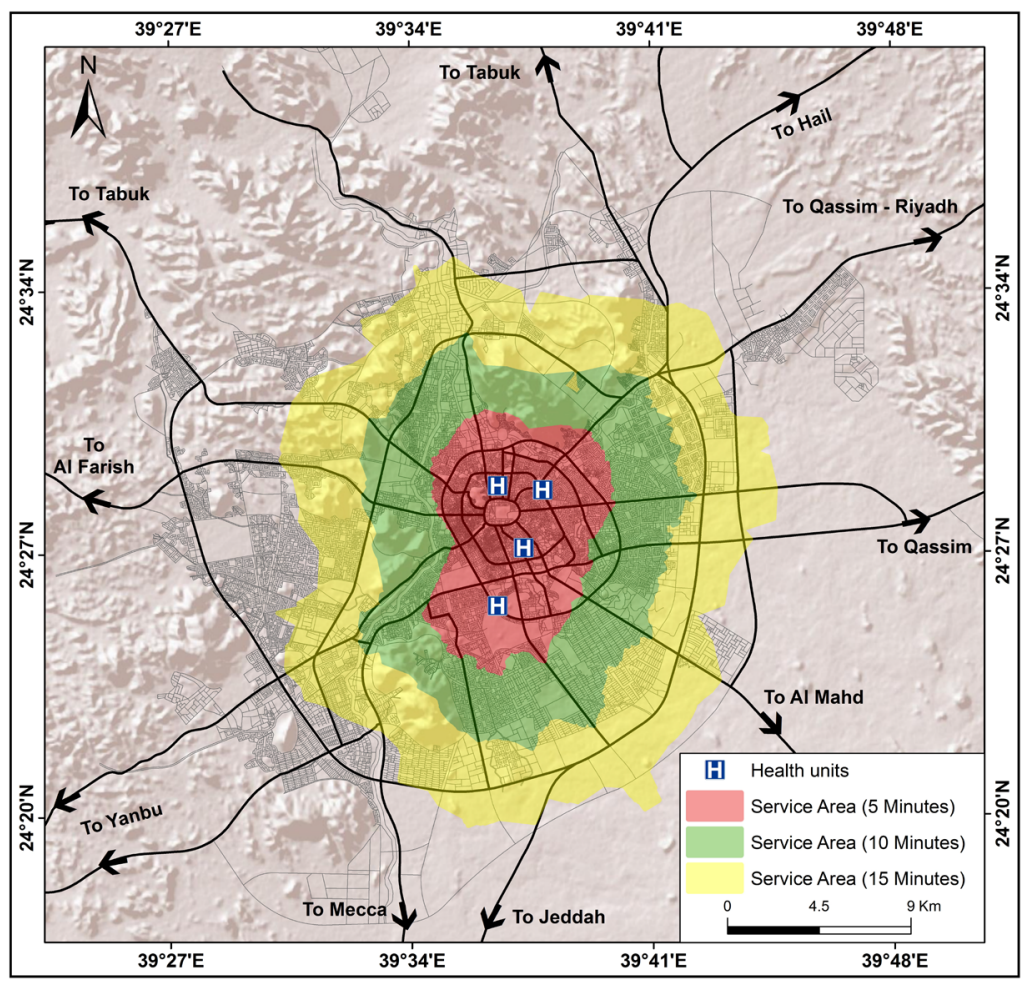

Figure 12. Accessibility to health units based on service area analysis. 
The number of districts that cannot access the Red Crescent service in five minutes is 31 districts constituting 29\% of the total districts in Al-Al-Madinah, which are: Ash-Sharae', Umm As-Suyoouf, Khakh, Al-Muzayin, An-Naqmi, Al-Matar, Al-Khadra', Abu Sidr, As-Sahwa, Sadd Al-Ghaba, the industrial city, As-Sahlouj, Al-Balqa', Ar-Rummanah, Al-Ghaba, Hadouda', Kitanna, Al-Hafia, Wadi Al-Hamed, Wadi Al-Battan, Ash-Shafiyah, As-Sadiqiah, Al-Mifrhat, AzZahra, Nubala', Rahat, Al-Jissa, Al-Baraka, An-Nakhil, Aira, and Tiba.

The number of districts that can access the Red Crescent service within ten minutes via the road network and according to the speed limit is 101 of the 107 districts in Al-Madinah constituting 94.4\% of the total districts in Al-Madinah, and the number of districts that cannot access the service The Red Crescent in ten minutes is six districts constituting 5.6\% of the total districts in Al-Madinah and these districts are: As-Sahwa, Abu Sidr, Sadd Al-Ghaba, Al-Balqa', Ketana, and Wadi Al-Hamed. All districts of Al-Madinah can access the Red Crescent service in fifteen minutes via Road network according to the speed limit, Figure 13.

\subsection{Area of Coverage of Health Services Combined for Districts in Al-Madinah}

At this stage the algebraic addition Raster's Sum was performed for the maps of health services resulting from network analysis of 8 different health services: public hospitals, specialized hospitals, health units, healthcare centers, infirmaries, clinic complexes, Red Crescent Center, and ambulance facilities within the GIS environment Arc GIS From the Toolbox, and the Spatial Analysis Toolbox was selected Spatial Analyst Tool and a selection of calculations on maps was selected from it Map Algebra then the Raster Calculator tool. The results are as shown on the map (Figure 14), which shows the classification of the coverage area of health services in Al-Madinah in terms of access to health services as follows:

\subsubsection{Districts with High Health Services: (Coverage Ranges from $90 \%$ to $100 \%$ )}

The results of the analysis of the spatial suitability map and the spatial efficiency map of the health services in Al-Madinah revealed that there are fifty-seven districts representing about $53.3 \%$ of the total districts of Madinah with very good level of health services, so they have high spatial suitability to live in for the ease of accessing these services with the least distance and fastest time. These districts are inhabited by most of the city's inhabitants. They cover an area of 213.8 square kilometers, representing $9.3 \%$ of the total area of the city. They are districts that have benefited from their unique geographic location and their organic fabric that has clear limits. The nucleus contains the old building of Al-Madinah Al-Munawwarah, and the distribution of services in these districts was influenced by the city plan, which in turn was affected by many geographical controls that was formed, especially the dense road network. Moreover, most of the districts in this group have high occupancy and construction rates and have 
high population density. All of these factors made this group have the best coverage of public services in Al-Madinah Al-Munawwarah.

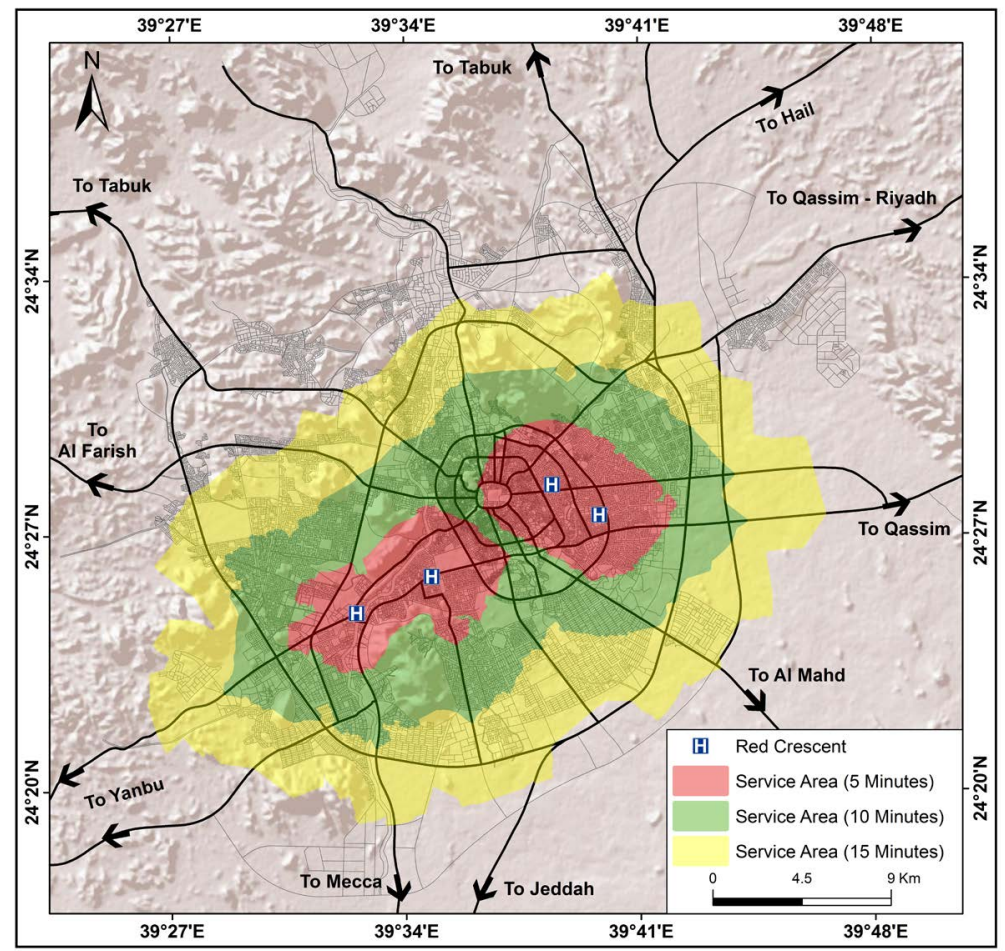

Figure 13. Accessibility to Red Crescent centers based on service area analysis.

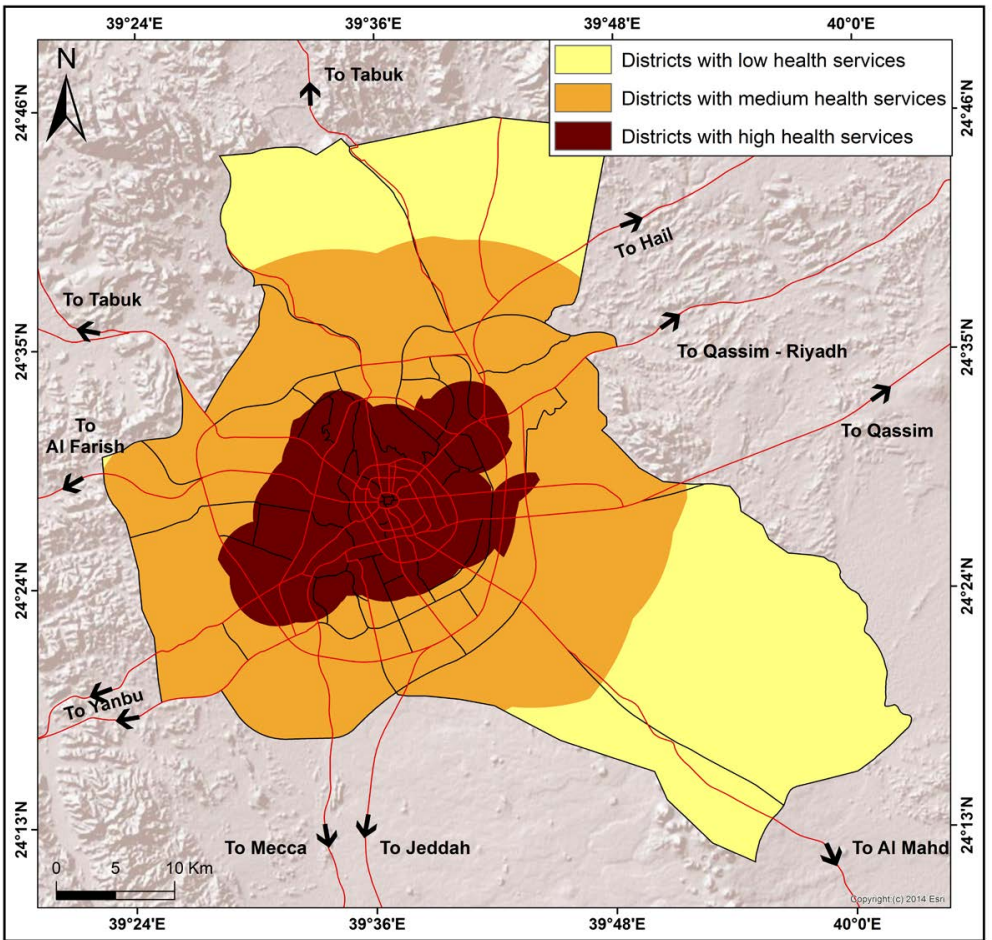

Figure 14. Classification of health services coverage based on arithmetic addition (Raster's Sum). 


\subsubsection{Districts with Medium Health Services: (60\% - 90\% Coverage)}

This group includes forty-six districts representing about $43 \%$ of the total districts in Al-Madinah, and is considered the second group in terms of population and population density in Al-Madinah, and they cover an area of about 880.8 square kilometers, representing about $38.4 \%$ of the total area of Al-Madinah.

\subsubsection{Districts with Low Health Services: (Covered Less Than 60\%)}

This group includes four districts representing about 3.7\% of the total districts in Al-Madinah, and these districts are inhabited by very few inhabitants of Al-Madinah, living on an area of about 1199.63 square kilometers, representing about $52.3 \%$ of the total area of Al-Madinah. These districts are: Umm AsSuyouf, Hadouda', As-Sahwa, and Sadd Al-Ghaba. These districts are concentrated in the north and south-east of Madinah, and the reasons for having low health services is due to its distance from the old nucleus of the city, the weakness of the road network, and its vast area in comparison to the rest of the city districts, which necessarily makes large parts of them inappropriate for housing, especially with the complex and intermingling topography of the city.

\subsection{Location-Allocation Model to Determine Current Needs and Future Planning of Health Services}

\subsubsection{General Hospitals}

The allocated locations, i.e. the centers of Al-Madinah districts that received the service of public hospitals in the prescribed response period (15 minutes) is 103 districts, which constitutes $96.3 \%$ of the 107 districts in Al-Madinah, and the number of sites that did not receive public hospitals service is four districts, which constitutes 3.7\% of the 107 districts in Al-Madinah. These districts are: Hadouda', Umm As-Suyouf, Sadd Al-Ghaba, and As-Sahwa. It has been suggested to add two more public hospitals in order to service the biggest number of unserviced districts, and at the same time the cost of construction is low, Figure 15.

\subsubsection{Specialized Hospitals}

The allocated locations, i.e. the centers of Al-Madinah districts that received the service of specialized hospitals in the prescribed response time (15 minutes), is 102 districts, which constitutes $95.3 \%$ of the total districts in Al-Madinah. The number of locations that did not receive the service of specialized hospitals is five districts constituting $4.7 \%$ of the 107 districts of Madinah. These districts are Hadouda', Umm As-Suyouf, Sadd Al-Ghaba, As-Sahwa and Wadi Al-Battan. It has been suggested to add three more hospitals in order to service the biggest number of unserviced districts, and at the same time the cost of construction is low, Figure 16.

\subsubsection{Primary Health Centers}

The allocated locations, i.e. the centers of Al-Madinah districts that received the service of health centers in the prescribed response time (15 minutes), is 103 districts, which constitutes $96.3 \%$ of the total districts in Al-Madinah. The number of locations that did not receive the service of health centers is four districts 
constituting 3.7\% of the 107 districts of Madinah. These districts are Hadouda', Umm As-Suyouf, Sadd Al-Ghaba, and As-Sahwa. It has been suggested to add two more health centers in order to service the biggest number of unserviced districts, and at the same time the cost of construction is low, Figure 17.

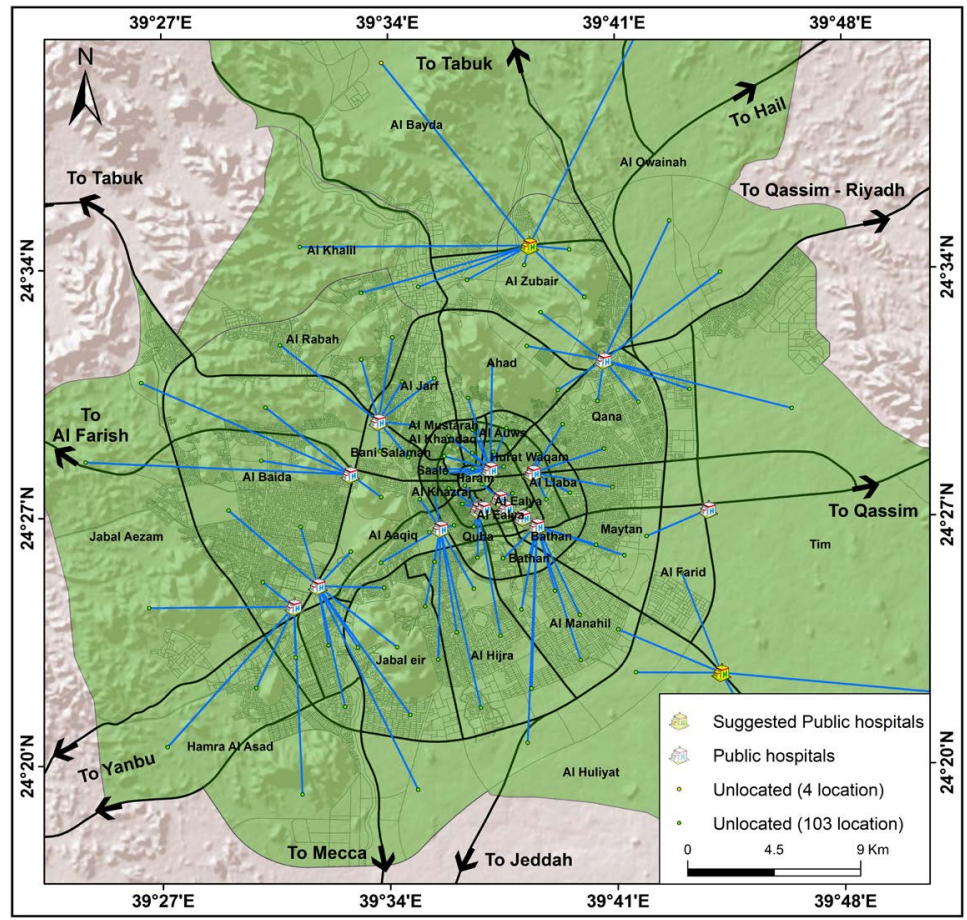

Figure 15. Suggested locations for public hospitals based on location-allocation.

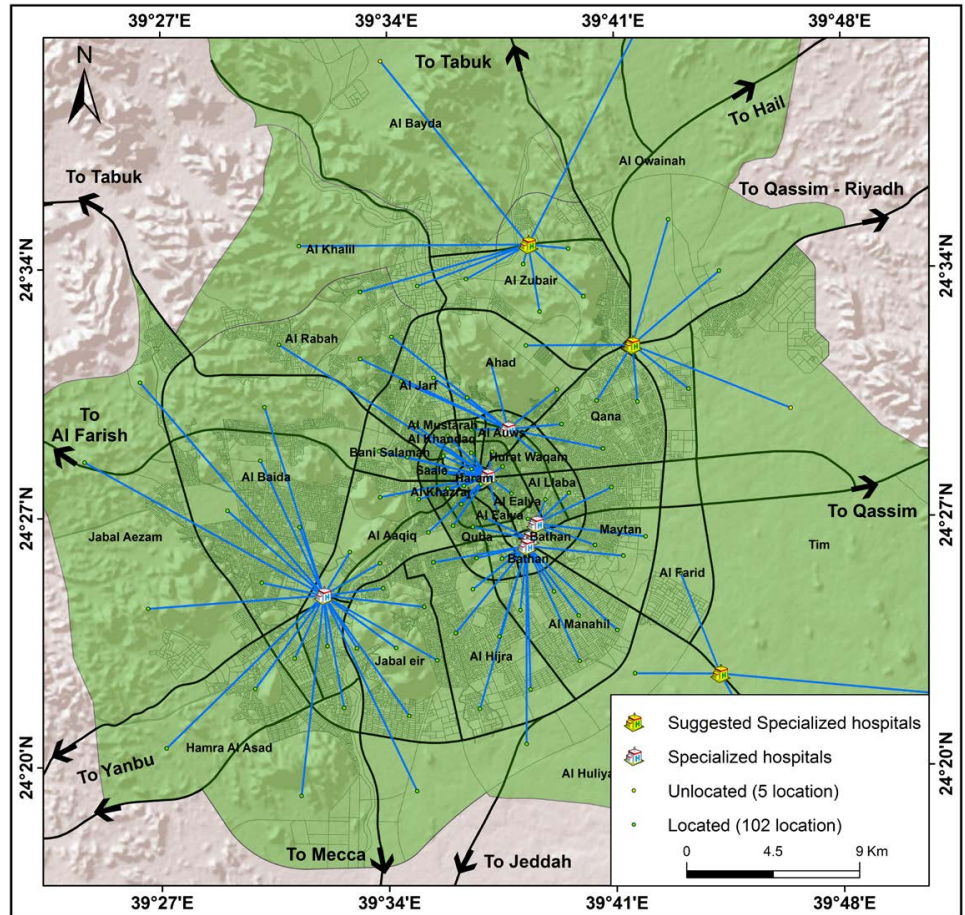

Figure 16. Suggested locations for specialized hospitals based on location-allocation. 


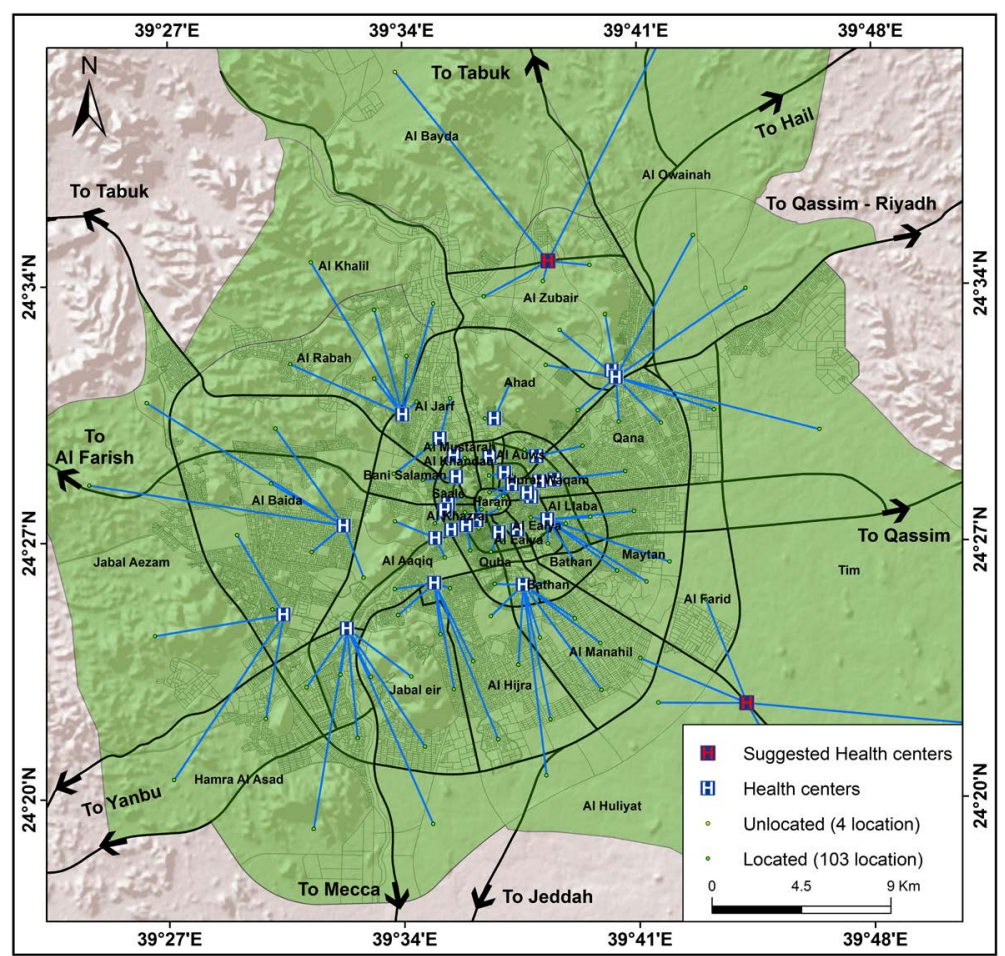

Figure 17. Suggested locations for health centers based on location-allocation.

\subsubsection{Ambulance Facilities}

The allocated locations, i.e. the centers of Al-Madinah districts that received the service of ambulance facilities in the prescribed response time (15 minutes), is 102 districts, which constitutes $95.3 \%$ of the total districts in Al-Madinah. The number of locations that did not receive the service of ambulance facilities is five districts constituting $4.7 \%$ of the 107 districts of Madinah. These districts are Hadouda', Umm As-Suyouf, Sadd Al-Ghaba, As-Sahwa and Wadi Al-Battana. It has been suggested to add three more ambulance facilities in order to service the biggest number of unserviced districts, and at the same time the cost of construction is low, Figure 18.

\subsubsection{Infirmaries}

The allocated locations, i.e. the centers of Al-Madinah districts that received the service of infirmaries in the prescribed response time (15 minutes), is 101 districts, which constitutes $94.4 \%$ of the total districts in Al-Madinah. The number of locations that did not receive the service of infirmaries is six districts constituting 5.6\% of the 107 districts of Madinah. These districts are Hadouda', Umm As-Suyouf, Sadd Al-Ghaba, As-Sahwa, Wadi Al-Battana, and the industrial city. It has been suggested to add four more infirmaries in order to service the biggest number of unserviced districts, and at the same time the cost of construction is low, Figure 19.

\subsubsection{Clinics Complex}

The allocated locations, i.e. the centers of Al-Madinah districts that received the 


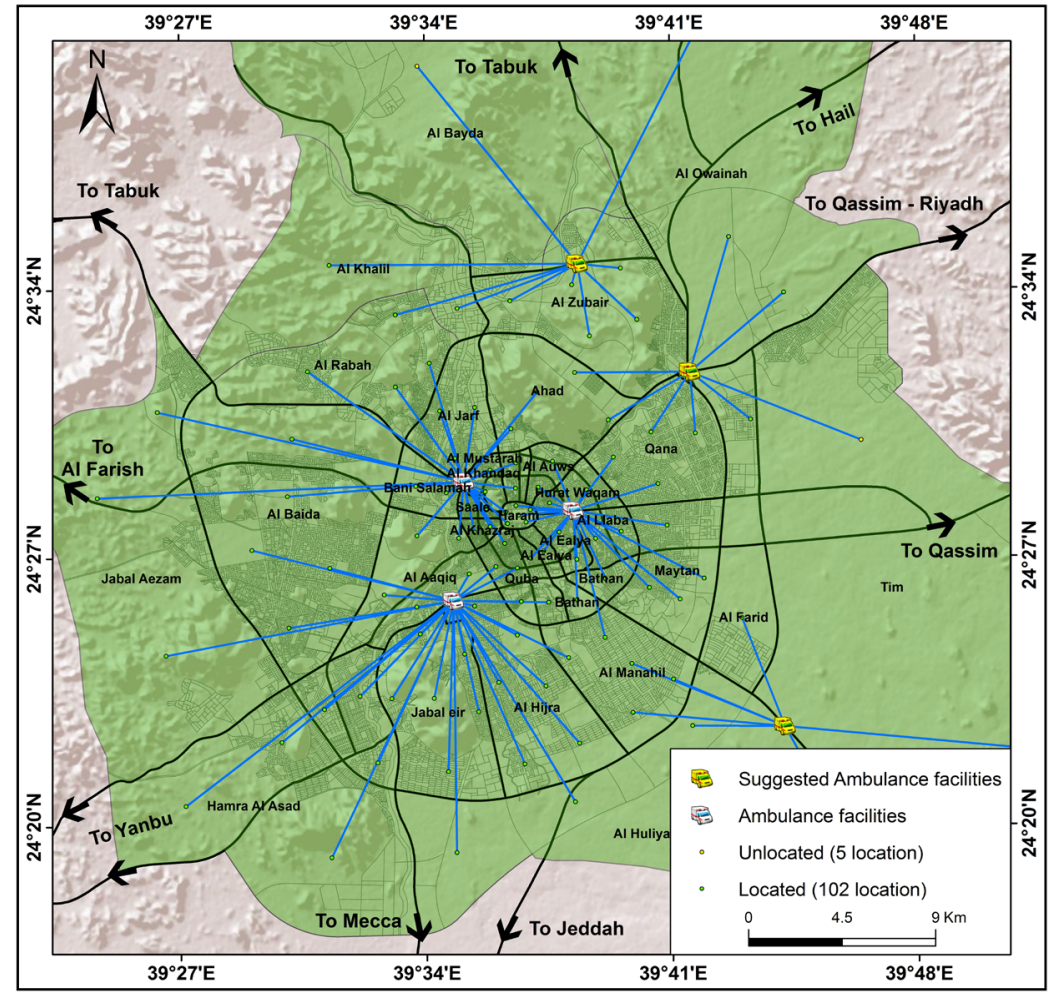

Figure 18. Suggested locations for ambulance facilities based on location-allocation.

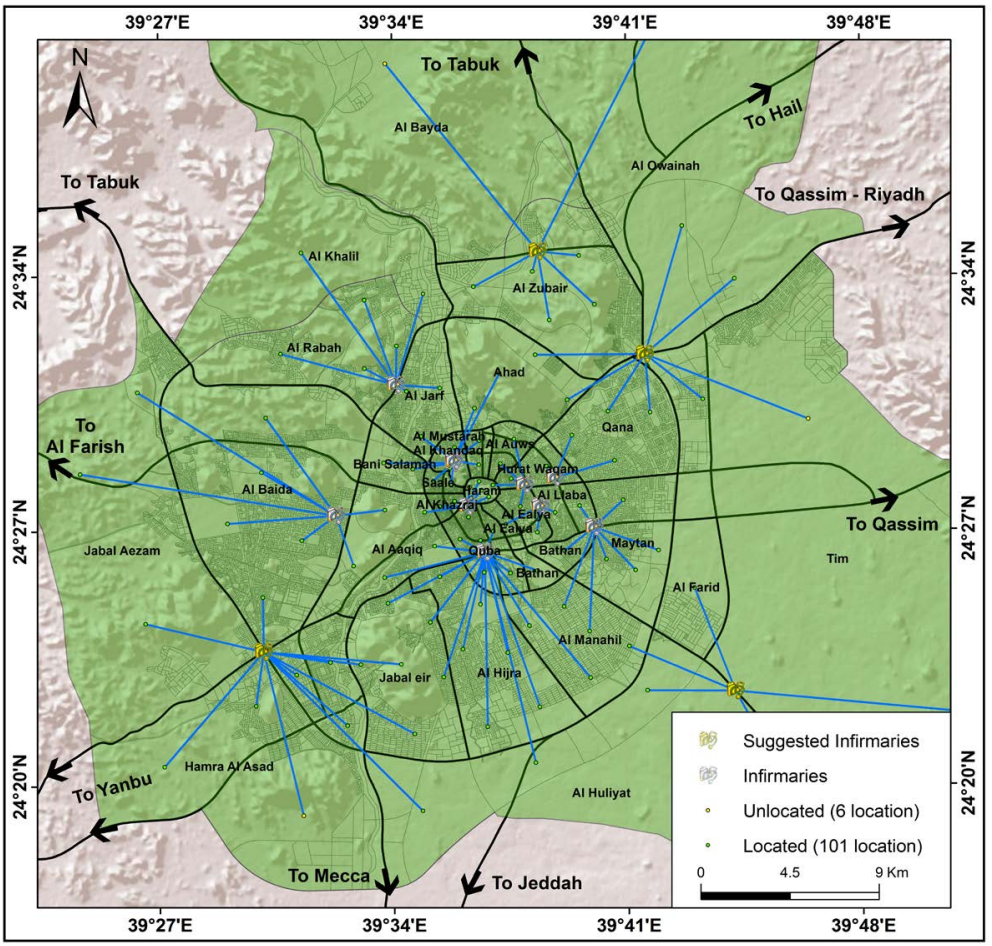

Figure 19. Suggested locations for infirmaries based on location-allocation.

service of clinics complexes in the prescribed response time (15 minutes), is 102 districts, which constitutes $95.3 \%$ of the total districts in Al-Madinah. The num- 
ber of locations that did not receive the service of clinics complexes is five districts constituting $4.7 \%$ of the 107 districts of Madinah. These districts are Hadouda', Umm As-Suyouf, Sadd Al-Ghaba, As-Sahwa and Wadi Al-Battana. It has been suggested to add three more clinics complexes in order to service the biggest number of unserviced districts, and at the same time the cost of construction is low, Figure 20.

\subsubsection{Health Units}

The allocated locations, i.e. the centers of Al-Madinah districts that received the service of health units in the prescribed response time ( 15 minutes), is 98 districts, which constitutes $91.6 \%$ of the total districts in Al-Madinah, While the number of locations that did not receive the service of health units is 9 districts, which constitutes $8.4 \%$ of the total number of districts in Al-Madinah. The districts are: Hadouda', Umm As-Suyouf, Sadd Al-Ghaba, As-Sahwa, Wadi AlBattana, the industrial city, Al-Mifrhat, As-Sahlouj, and Al-Balqa'. It has been suggested to add four more health units in order to service the biggest number of unserviced districts, and at the same time the cost of construction is low, Figure 21.

\subsubsection{Red Crescent Centers}

The allocated locations, i.e. the centers of Al-Madinah districts that received the service of Red Crescent centers in the prescribed response time (15 minutes), is 102 districts, which constitutes $95.3 \%$ of the total districts in Al-Madinah. The number of locations that did not receive the service of Red Crescent centers is five districts constituting $4.7 \%$ of the 107 districts of Madinah. These districts are Hadouda', Umm As-Suyouf, Sadd Al-Ghaba, As-Sahwa and Wadi Al-Battan. It has been suggested to add three more Red Crescent centers in order to service the biggest number of unserviced districts, and at the same time the cost of construction is low, Figure 22.

\section{Recommendations}

The management of the urban environment of the Saudi cities through the model of Al-Madinah Al-Munawwarah regarding assessment and planning of health services requires the application of advanced technology capable of identifying and analyzing the rapid variables affecting urban growth and land use change, which contributes to understanding the nature of planning and sustainable development in these environments that have experienced dynamic changes in which the old maps and traditional methods in conducting applied studies of actual feasibility in the face of the dynamics of urban growth; hence, the importance of this study in the application of the integration of accessibility models and site allocation in geographic information systems In order to improve spatial planning and environmental sustainability of health services in Al-Madinah Al-Munawwarah, this integration provides a planning framework to verify the efficiency of spatial distribution of health services and 
generate alternatives either by proposing an effective service or to improve an existing service.

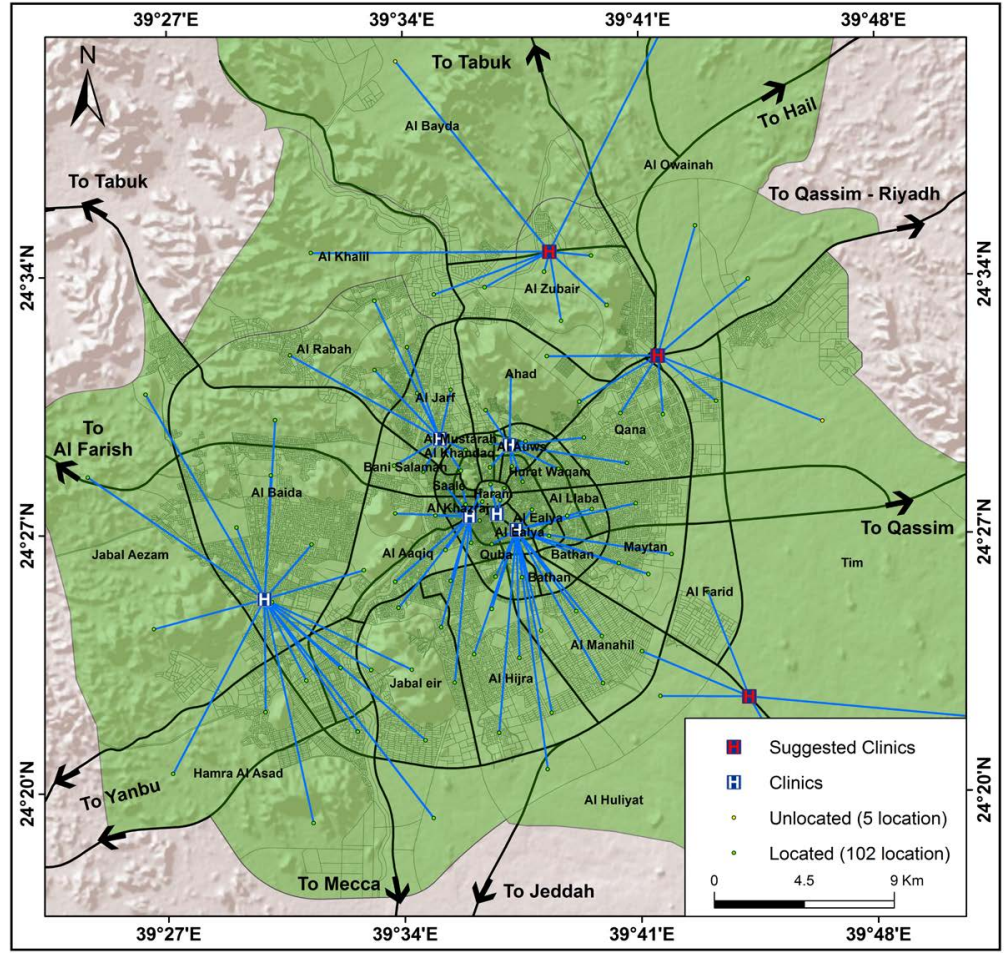

Figure 20. Suggested locations for clinic complexes based on location-allocation.

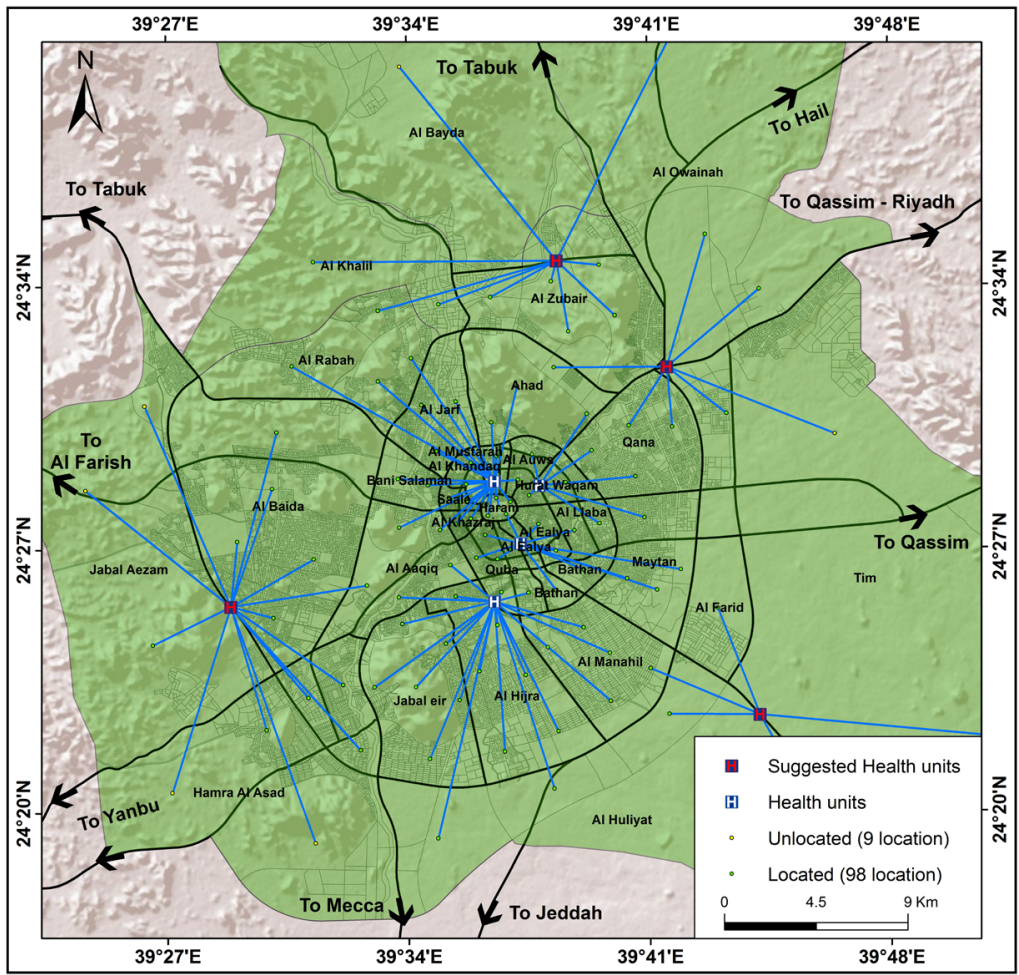

Figure 21. Suggested locations for health units based on location-allocation. 


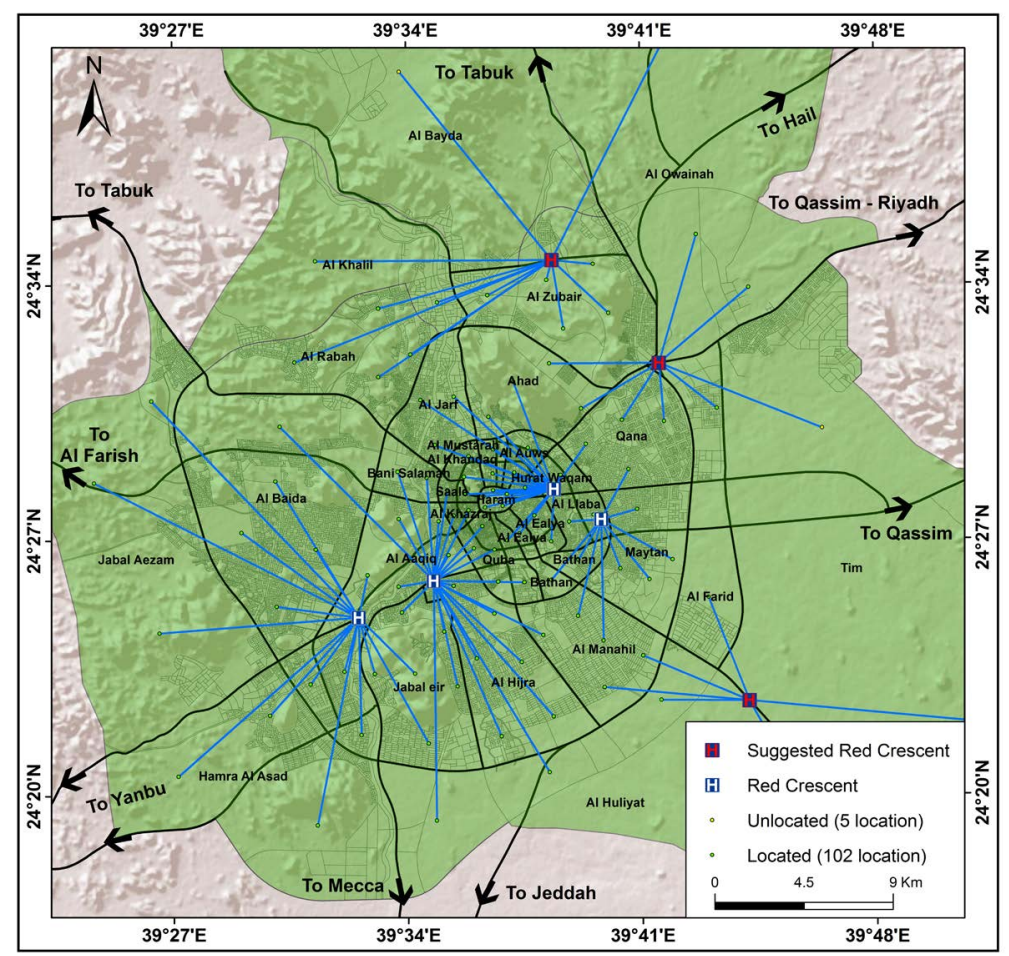

Figure 22. Suggested locations for Red Crescent centers based on location-allocation.

Health services are one of the main elements in the urban development processes in Al-Madinah Al-Munawwarah, and the lack of quality levels in terms of number or spatial distribution is a strong determinant of the process of its sustainable urban development, especially in light of the growing and excessive population and urban expansion of the growing functional, regional and administrative role of Al-Madinah Al-Munawwarah which gives it additional planning burdens in addition to poor coverage areas for health services accessibility in Al-Madinah Al-Munawwarah during the intervals of five, ten and fifteen minutes, which created a negative impact on the management of the current urban environment.

In order to find planning solutions to reduce the dimensions of those problems, the study recommends some suggestions that would provide and improve the reality of health services in Al-Madinah Al-Munawwarah through the redistribution of health services in Al-Madinah in proportion to the number and need of the population of them in an orderly manner serving all districts of Al-Madinah. This requires the filling of the current shortage of health services which is represented by twenty-four locations with two public hospitals, three specialized hospitals, two health centers, three ambulance facilities, four clinics, three clinic complexes, four health units and three Red Crescent centers.

The study also recommends putting the results reached before the decision-makers when developing urban planning strategies to implement them in sustainable urban development plans; developing and improving the efficiency of the infrastructure for the purpose of managing them and keeping abreast of 
changes over time; introducing modern technologies commensurate with the need of the population of Al-Madinah; adopting the ease of access to public services as one of the main factors when the locations on these services are allocated and planned in Al-Madinah in addition to adopting foundations and standards of urban planning, and the adoption of statistical and spatial analysis methods in GIS when evaluating and planning health services in cities.

\section{Conclusions}

Al-Madinah Al-Munawwarah has faced many challenges in sustainable urban development during the past thirty years, and perhaps the most prominent of these challenges is the rapid urbanization without the availability of public services that keep pace with this increase, especially health services. The religious function of Al-Madinah Al-Munawwarah is the main powerhouse of its constructional and administrative growth, and its constructional composition which greatly impacted the effectiveness of the geographic distribution of health services. The number of inhabitants of Al-Madinah has almost doubled in a period not exceeding 36 years (1394-1440 AH) as a result of the natural increase in the number of population and the increase of the number of incoming residents. Hence, the city expanded, its urbanization flourished, and its districts multiplied. As a result, there was an increasing pressure on the urban area at rates that exceed the city's ability to provide various health services and jobs to its community in terms of quantity and quality, which resulted in many problems related to the lack of various forms of health services, chaos in the use of land, the emergence of squatter areas, and the decline of health services. The adoption of new urban plans without taking into account the planning foundations has also contributed to the chaos in the use of land, the inability of some districts in the city to provide health services to the population at the appropriate level with no clear vision of the prevailing uses at the district level and some and at the city level as a whole, and this has affected the dispersion of health services and divergence, and the lack of supply to serve the population of the city.

This was reflected in the weak coverage areas for accessibility to health services in the city during the intervals of five, ten and fifteen minutes, which ranged between $63 \%-84 \%$, where coverage areas for health services of the type of health units ranked last by about $63 \%$, while coverage areas of health services of the primary healthcare centers are ranked first by $84 \%$, and there are fifty-seven districts representing about $53.3 \%$ of the total number of districts in Al-Madinah where the level of health services is very good with coverage ranging from $90 \%$ to $100 \%$. Therefore, these districts are of high spatial convenience for living in them for ease of access to those Services with the lowest distance and as soon as possible, there are about forty-six districts representing about $43 \%$ of the total districts of Al-Madinah with medium services with a coverage rate ranging from $60 \%$ to $90 \%$, while there are about four districts representing about $3.7 \%$ of the total districts of Al-Madinah with Low health services where coverage is no 
more than $60 \%$.

Al-Madinah is currently unable to meet the needs of its population of health services at the present time the need for health services reached twenty-four sites with two public hospitals, three specialized hospitals, two health centers, three ambulance facilities, four clinics, three clinics complexes, four health units, and three Red Crescent Centers.

\section{Conflicts of Interest}

The author declares no conflicts of interest regarding the publication of this paper.

\section{References}

[1] Croser, J.L. (2003) Trauma Care Systems in Australia. Injury, 34, 649-651. https://doi.org/10.1016/S0020-1383(03)00157-8

[2] Almer, C. and Goeschl, T. (2011) The Political Economy of the Environmental Criminal Justice System: A Production Function Approach. Public Choice, 148, 611-630. https://doi.org/10.1007/s11127-010-9687-5

[3] Germani, A.R., Morone, P. and Testa, G. (2014) Environmental Justice and Air Pollution: A Case Study on Italian Provinces. Ecological Economics, 106, 69-82. https://doi.org/10.1016/j.ecolecon.2014.07.010

[4] Cory, D.C. and Rahman, T. (2009) Environmental Justice and Enforcement of the Safe Drinking Water Act: The Arizona Arsenic Experience. Ecological Economics, 68, 1825-1837. https://doi.org/10.1016/j.ecolecon.2008.12.010

[5] Gosselin, R.A., Spiegel, D.A., Coughlin, R. and Zirkle, L.G. (2009) Injuries: The Neglected Burden in Developing Countries. Bulletin of the World Health Organization, 87, 246. http://www.who.int/bulletin/volumes/87/4/08-052290/

[6] Li, H., Liu, T. and Yin, X. (2012) Review and Analysis on Research Status of Trauma Emergency in Recent Ten Years in China. Journal of Traumatic Surgery, 14, 104-107.

[7] Albert, J. and Phillips, H. (2003) Trauma Care Systems in the United Kingdom. Injury, 34, 728-734. https://doi.org/10.1016/S0020-1383(03)00151-7

[8] Rahman, S. and Smith, D. (2000) Use of Location-Allocation Models in Health Services Development Planning in Developing Nations. European Journal of Operational Research, 123, 437-452. https://doi.org/10.1016/S0377-2217(99)00289-1

[9] Wang, L. (2007) Immigration, Ethnicity and Accessibility to Culturally Diverse Family Physicians. Health \& Place, 13, 656-671.

https://doi.org/10.1016/j.healthplace.2006.10.001

[10] Luo, W. and Whippo, T. (2012) Variable Catchment Sizes for the Two-Step Floating Catchment Area (2SFCA) Method. Health \& Place, 18, 789-795.

https://doi.org/10.1016/j.healthplace.2012.04.002

[11] Dai, D. (2010) Black Residential Segregation, Disparities in Spatial Access to Health Care Facilities and Late-Stage Breast Cancer Diagnosis in Metropolitan Detroit. Health \& Place, 16, 1038-1052. https://doi.org/10.1016/j.healthplace.2010.06.012

[12] Thisse, J. and Wildasin, D. (1992) Public Facility Location and Urban Spatial Structure: Equilibrium and Welfare Analysis. Journal of Public Economics, 48, 83-118. https://doi.org/10.1016/0047-2727(92)90043-F

[13] Alexiadis, S. (2018) Compatibility between Equity and Efficiency. In: The Dilemma of Regional Policy, Palgrave Pivot, Cham, 73-105. 
https://doi.org/10.1007/978-3-319-68900-5_4

[14] Deverteuil, G. (2000) Reconsidering the Legacy of Urban Public Facility Location Theory in Human Geography. Progress in Human Geography, 24, 47-69. https://doi.org/10.1191/030913200668094045

[15] Song, Z.N. (2016) Competitive Public Facilities Location Decision: Concept, Location Selection Principle and Model Construction. Scientia Geographica Sinica, 36, 1485-1494.

[16] Song, Z.N., Yan, T.G., Liu, T. and Huang, T. (2016) A New Gravity P-Median Model and Empirical Test in Urban Comprehensive Hospital Location Decision Making: Take Wuxi as an Example. Progress in Geography, 35, 420-430.

[17] Rahman, S. and Smith, D. (1996) The Efficiency of Inefficiency: The Deployment of Health Facilities in Rural Bangladesh. In: Alauddin, M. and Hasan, S., Eds., Bangladesh: Economy, People and the Environment, Department of Economics, University of Queensland, Brisbane, 197-209.

[18] Fisher, H. and Rushton, G. (1979) Spatial Efficiency of Service Locations and the Regional Development Process. Papers of the Regional Science Association, 42, 83-97. https://doi.org/10.1007/BF01935147

[19] Tekiner, H. (2014) Pharmacy in Turkey: Past, Present and Future. Pharmazie, 69, 477-480. https://www.ncbi.nlm.nih.gov/pubmed/24974586

[20] Hetzel, B. (1978) Basic Health Care in Developing Countries. Oxford University Press, Oxford.

[21] Phillips, D. (1990) Health and Health Care in Third World. Essex Longman, London.

[22] Bennett, W. (1981) A Location-Allocation Approach to Health Care Facility Location: A Study of the Undoctored Population in Lansing, Michigan. Social Science \& Medicine. Part D: Medical Geography, 15, 305-312. https://doi.org/10.1016/0160-8002(81)90006-X

[23] Phillips, D. (1986) Urban Hospital Location: London Research Series in Geography No 4: Leslie Mayhew George Allen and Unwin, London. Cities, 3, 357-358. https://doi.org/10.1016/0264-2751(86)90080-6

[24] Taylor, E. (1982) Health Services Forum. Geneva, 395.

[25] Meade, S., Johm, W. and Wlibert, M. (1988) Medical Geography. The Guilford Press, New York.

[26] Guagliardo, M. (2004) Spatial Accessibility of Primary Care: Concepts, Methods and Challenges. International Journal of Health Geographics, 3, 3-14. https://doi.org/10.1186/1476-072X-3-3

[27] Khan, A. (1992) An Integrated Approach to Measuring Potential Spatial Access to Health Care Services. Socio-Economic Planning Sciences, 26, 275-287. https://doi.org/10.1016/0038-0121(92)90004-O

[28] Joseph, E. and Bantock, P. (1982) Measuring Potential Physical Accessibility to General Practitioners in Rural Areas: A Method and Case Study. Social Science \& Medicine, 16, 85-90. https://doi.org/10.1016/0277-9536(82)90428-2

[29] Luo, W. and Wang, F. (2003) Measures of Spatial Accessibility to Health Care in a GIS Environment: Synthesis and a Case Study in the Chicago Region. Environment and Planning B: Planning and Design, 30, 865-884. https://doi.org/10.1068/b29120

[30] Cho, C. (1998) An Equity-Efficiency Trade-off Model for the Optimum Location of Medical Care Facilities. Socio-Economic Planning Sciences, 32, 99-112. https://doi.org/10.1016/S0038-0121(97)00007-4 
[31] Yasenovskiy, V. and Hodgson, J. (2007) Hierarchical Location-Allocation with Spatial Choice Interaction Modelling. Annals of the Association of American Geographers, 97, 496-511. https://doi.org/10.1111/j.1467-8306.2007.00560.x

[32] Baray, J. and Cliquet, G. (2013) Optimizing Locations through a Maximum Covering/p-Median Hierarchical Model: Maternity Hospitals in France. Journal of Business Research, 66, 127-132. https://doi.org/10.1016/j.jbusres.2012.09.003

[33] Guerriero, F., Miglionico, G. and Olivito, F. (2016) Location and Reorganization Problems: The Calabrian Health Care System Case. European Journal of Operational Research, 250, 939-954. https://doi.org/10.1016/j.ejor.2015.09.064

[34] Marks, A.P., Thrall, G.I. and Arno, M. (1992) Siting Hospitals to Provide Cost-Effective Health Care. Geographic Information System, 2, 58-66.

[35] Brown, L. and Barnett, J.R. (2004) Is the Corporate Transformation of Hospitals Creating a New Hybrid Health Care Space? A Case Study of the Impact of Co-Location of Public and Private Hospitals in Australia. Social Science \& Medicine, 58, 427-444. https://doi.org/10.1016/S0277-9536(03)00163-1

[36] Tulchinsky, T.H. and Varavikova, E.A. (2014) Chapter 12-Planning and Managing Health Systems. In: Tulchinsky, T.H., Varavikova, E.A. and Bickford, J.D., Eds., The New Public Health, 3rd Edition, Academic Press, San Diego, 613-641. https://doi.org/10.1016/B978-0-12-415766-8.00012-4

[37] Moscelli, G., Siciliani, L., Gutacker, N. and Gravelle, H. (2016) Location, Quality and Choice of Hospital: Evidence from England 2002-2013. Regional Science and Urban Economics, 60, 112-124. https://doi.org/10.1016/j.regsciurbeco.2016.07.001

[38] Shortt, N.K. and Moore, A.J. (2006) Functional Localities: An Integrated Spatial Approach towards Health Care Locality Definition. GeoJournal, 67, 27-40. https://doi.org/10.1007/s10708-006-9005-4

[39] Wu, C., Lin, C. and Chen, H. (2007) Optimal Selection of Location for Taiwanese Hospitals to Ensure a Competitive Advantage by Using the Analytic Hierarchy Process and Sensitivity Analysis. Building and Environment, 42, 1431-1444. https://doi.org/10.1016/j.buildenv.2005.12.016

[40] Zhang, W., Cao, K., Liu, S. and Huang, B. (2016) A Multi-Objective Optimization Approach for Health-Care Facility Location-Allocation Problems in Highly Developed Cities Such as Hong Kong. Computers, Environment and Urban Systems, 59, 220-230. https://doi.org/10.1016/j.compenvurbsys.2016.07.001

[41] Schweikhart, B. and Smith, L. (1993) Location and Service Mix Decisions for a Managed Health Care Network. Socio-Economic Planning Sciences, 27, 289-302. https://doi.org/10.1016/0038-0121(93)90021-A

[42] Mestre, M., Oliveira, D. and Barbosa-Póvoa, P. (2015) Location-Allocation Approaches for Hospital Network Planning under Uncertainty. European Journal of Operational Research, 240, 791-806. https://doi.org/10.1016/j.ejor.2014.07.024

[43] Ammari, F., Ogawa, K. and Miyagi, T. (2000) Spatial Interaction Model in HealthCare Facility Location-Allocation. Infrastructure Planning Review, 17, 219-228.

[44] Abdulkader, M. (2018) Using GIS for Determining Variations in Health Access in Jeddah City, Saudi Arabia. ISPRS International Journal of Geo-Information, 7, 254. https://doi.org/10.3390/ijgi7070254

[45] Francisco, J., José, A., Emilio, H., Silvia, L., Jin, S., María, N. and Alejandro, R. (2017) Network and Spatial Analysis to Assess and Guide Decisions about Equitable Accessibility to Health Services: The Public Palliative Care System in Extremadura (Spain). Diversity and Equality in Health and Care, 14, 184-192. https://doi.org/10.21767/2049-5471.1000110 
[46] Chéri G., Gerbrand, M., Peter, S., David, M. and Mark, W. (2014) Planning for Emergency Services Using GIS-Based Geographic Accessibility Analysis. Town and Regional Planning, 64, 1-12. https://www.ajol.info/index.php/trp/article/view/116216/105743

[47] Rodzi, A. and Vini, I. (2013) Facility Location Models Development to Maximize total Service Area. Theoretical and Empirical Researches in Urban Management, Special Number 1S.

https://www.questia.com/library/journal/1G1-210725580/facility-location-models-d evelopment-to-maximize-total

[48] Hunadi, M. (2014) Measuring Access to Primary Health Care: Use of a GIS-Based Accessibility Analysis. Built Environment, Council for Scientific and Industrial Research, 19-22. http://hdl.handle.net/10204/7913

[49] Gustavo, B. (2013) Location-Allocation Models Applied to Urban Public Services Spatial Analysis of Primary Health Care Centers in the City of Lugan, Argentina, Hungarian Geographical Bulletin, 62, 387-408.

http://www.mtafki.hu/konyvtar/kiadv/HunGeoBull2013/HunGeoBull_2013_4_387408.pdf

[50] Gina, P., Mera, A., Fernando, F. and Ricardo, A. (2015) Location-Allocation and Accessibility Models for Improving the Spatial Planning of Public Health. PLoS ONE, 10, e0119190. https://doi.org/10.1371/journal.pone.0119190

[51] Kemboi, T. and Waithaka, E. (2013) GIS Location-Allocation Model in Improving Accessibility to Health Care Facilities: A Case Study of Mt. Elgon Sub-County. International Journal of Science and Research, 4, 3306-3310. https://pdfs.semanticscholar.org/b151/2510750c2a6721dbfe0c33a477f0fda55e09.pdf ?.ga=2.98046047.1378241492.1568455666-514517534.1566633811

[52] Eren, Ö., Ayşenur, U., Mehmet, E., Cihan, Ç. and Selçuk, K. (2017) Optimizing the Location-Allocation Problem of Pharmacy Warehouses: A Case Study in Gaziantep. An International Journal of Optimization and Control: Theories \& Applications, 7, 117-129. https://doi.org/10.11121/ijocta.01.2017.00373

[53] Beheshtifar, S. and Alimoahmmadi, A. (2015) A Multiobjective Optimization Approach for Location-Allocation of Clinics. International Transactions in Operational Research, 22, 313-328. https://doi.org/10.1111/itor.12088

[54] Widener, J. and Horner, W. (2011) A Hierarchical Approach to Modeling Hurricane Disaster Relief Goods Distribution. Journal of Transport Geography, 19, 821 828. https://doi.org/10.1016/j.jtrangeo.2010.10.006

[55] ESRI. Arc GIS, Version 10X Help. http://desktop.arcgis.com/zh-cn/arcmap/latest/extensions/network-analyst/types-of-n etwork-analyses.htm\#ESRI_SECTION1_DEAE22E63F944F6C958668B8C4AA96DA

[56] Hakimi, S. (1964) Optimum Locations of Switching Centers and the Absolute Centers and Medians of a Graph. Operations Research, 12, 450-459.

https://www.jstor.org/stable/168125

https://doi.org/10.1287/opre.12.3.450 